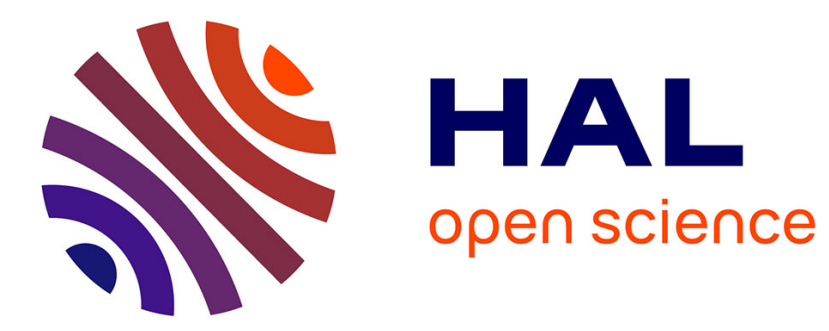

\title{
The Firm's Management in Production: Management, Firm and Time Effects in an Indian Ocean Tuna Fishery
}

François-Charles Wolff, Dale Squires, Patrice Guillotreau

\section{To cite this version:}

François-Charles Wolff, Dale Squires, Patrice Guillotreau. The Firm's Management in Production: Management, Firm and Time Effects in an Indian Ocean Tuna Fishery. 2012. hal-00726694

\section{HAL Id: hal-00726694 \\ https://hal.science/hal-00726694}

Preprint submitted on 31 Aug 2012

HAL is a multi-disciplinary open access archive for the deposit and dissemination of scientific research documents, whether they are published or not. The documents may come from teaching and research institutions in France or abroad, or from public or private research centers.
L'archive ouverte pluridisciplinaire HAL, est destinée au dépôt et à la diffusion de documents scientifiques de niveau recherche, publiés ou non, émanant des établissements d'enseignement et de recherche français ou étrangers, des laboratoires publics ou privés. 
EA 4272

\title{
The Firm's Management in Production: Management, Firm and Time Effects in an Indian Ocean Tuna Fishery
}

\author{
François-Charles Wolf* \\ Dale Squires ${ }^{* *}$ \\ Patrice Guillotreau ${ }^{\star \star *}$
}

$2012 / 35$

**LEMNA - Université de Nantes et INED - Paris - France

${ }^{* *}$ National Marine Fisheries Service and University of California San Diego, La Jolla, California, USA *Université de Nantes - LEMNA - France

Laboratoire d'Economie et de Management Nantes-Atlantique Université de Nantes

Chemin de la Censive du Tertre - BP 52231

44322 Nantes cedex 3 - France 


\title{
The Firm's Management in Production: Management, Firm and Time Effects in an Indian Ocean Tuna Fishery ${ }^{\#}$
}

\author{
François-Charles Wolff ${ }^{*}$, Dale Squires ${ }^{* *}$ and Patrice Guillotreau ${ }^{* *}$
}

\author{
August 2012 \\ First revision, American Journal of Agricultural Economics
}

\begin{abstract}
The firm's management in production is a critical, but unobserved input. Within a panel data framework, the firm's management and firm effects have to date been conflated. Exploiting variability in the managerial dimension, this paper identifies the firm's management from firm and time effects in a production function using a three-way fixed effect model and a unique panel data set tracking multiple managers for each firm in each year for an industry over 27 years. We also allow for time-varying firm management through learning. The model is applied to the French purse-seine fleet harvesting tunas in the Indian Ocean. We find that fishing hours and number of sets on floating objects and on free-swimming schools explain more than $70 \%$ of variation in tuna catches over the period. The skipper and vessel fixed effects have a rather similar influence (around $5 \%$ each). Skipper learning-by-doing as measured by experience and job tenure plays no significant role, meaning that managerial ability is time-invariant in this industry.
\end{abstract}

Key Words: Firm's management, firm effect, management effect, time effect, tuna fisheries

JEL Codes: Q22, D24

\footnotetext{
\# We are indebted to two anonymous reviewers and to the editor, David Hennessy, for their very helpful comments and suggestions on a previous draft. We also would like to thank seminar participants at the FAD conference in Tahiti (Ifremer) and at the Regards workshop (University of Reims). The fisheries data analysed in this publication were collected by the Mixed Research Unit 212 'Exploited Marine Ecosystems' of the Institut de Recherche pour le Développement (IRD) through the EU-funded Data Collection Framework [DCF, Reg (EC) 1543/2000 and 199/2008]. We wish to acknowledge the contributions of ORTHONGEL, the staff of the 'Observatoire Thonier', and all the technicians and fishermen that have been involved in data collection, processing, and management. We are particularly grateful to Patrice Dewals for his assistance with data and expertise on purse seine fisheries of the Indian Ocean. We also acknowledge the support of the French Agence Nationale de la Recherche (ANR), under grant CEP (changements environnementaux planétaires) MACROES (ANR09-CEP-003) and the international projects MADE (European Commission FP7) and CLIOTOP (IMBER). The results are not necessarily those of the National Marine Fisheries Service.

* LEMNA, Université de Nantes, and INED, Paris, France.

E-mail: francois.wolff@univ-nantes.fr http://www.sc-eco.univ-nantes.fr/ fcwolff/

${ }^{* *}$ National Marine Fisheries Service and University of California San Diego, La Jolla, California, USA.

E-mail: dale.squires@noaa.gov

${ }^{* * *}$ LEMNA, Université de Nantes, France.

E-mail: patrice.guillotreau@univ-nantes.fr
} 


\section{Introduction}

The firm's management has long been recognized as a critical component of production decisions (Mundlak, 1961, Hoch, 1955) ${ }^{1}$. It has traditionally been specified as a fixed input, dividing the managerial function into "uncertainty bearing" and "supervision and coordination" (Mundlak, 1961). This critical input is unobserved, which introduces considerable complexity to the specification and estimation of production technologies, explaining why it was ultimately treated as a residual.

Beginning with Mundlak (1961) and Hoch (1962), the firm management literature has focused on fixed effect estimation of production functions with panel data (Massell, 1967, Griliches and Mairesse, 1998, Mundlak, 1978, 2001), with lesser attention given to random effects (Squires and Kirkley, 1999) and comparative indexes of management (Mundlak, 1961, Medford, 1986, Bloom and van Reenen, 2007). Schmidt and Sickles (1984) extended the fixed effect specification to be interpreted as time-invariant technical efficiency. When technical efficiency is estimated from a stochastic production frontier, the firm's management can be interpreted as time varying and can be related to measures of the manager's human capital (Kirkley et al., 1998) ${ }^{2}$.

The firm's management in fishing industries, through the skipper effect or the "good captain hypothesis", has a long tradition of discussion ${ }^{3}$. The firm's management can also be viewed as part of the larger issue of unobserved heterogeneity between firms and unobserved inputs in general, which extends beyond the individual firm's management to include multiple unobserved factors that influence the firm's production (Mundlak, 1961). When management is specified as a residual, it includes the effects of factors that do not depend on the management, but rather on the firm's particular environmental conditions.

The firm's management literature, when specifying fixed or random effects or indexes of management, has heretofore assumed that management is time invariant in the sense that the same manager or management team remains in place over time. This implicit assumption of time-invariant management does not allow for different managers or management teams over time in any given firm, does not allow for management learning over time. Besides, it conflates the management and other sources of unobserved firm heterogeneity that are not captured by the observed factors of production or time effects, as initially observed by Mundlak (1961). The time-varying technical efficiency and management literature has similarly implicitly assumed (through lack of specification) a constant or time invariant management team, although the performance (as measured by technical

\footnotetext{
${ }^{1}$ When discussing early economic analysis of the firm's production, Mundlak (2001, p. 6) states that management was recognized as an input, but "[t]he productive agent management has been excluded since there is no satisfactory index of inputs for this factor" [Tintner and Brownlee (1944, p. 566)]. Allusions were also made to the importance of input quality. Heady (1946) expressed similar concerns about the quality issue and the omission of management".

${ }^{2}$ Technical efficiency can also provide a measure of excess fishing capacity when the firm is inefficiently managed or capital is underutilized and variable inputs are fully utilized.

${ }^{3}$ See the literature reviews in Viswanathan et al. (2002) and Pascoe and Coglan (2002).
} 
efficiency) is allowed to vary over time ${ }^{4}$.

In this paper, we address the unobserved heterogeneity between firms and unobserved inputs in general, which extends beyond the individual firm's management to include multiple unobserved factors that influence the firm's production. Working within the fixed effect specification of firm management, in which management is fixed, additive, and neutral with respect to supply and input demand shifters, the paper further distinguishes the firm's management effect from a general firm effect or more broadly, from the effect of the firm's general production conditions (the environment as nature, technical change) and industry structure on the performance of the firm. We further allow for potential time-varying firm management, in which the firm's manager can learn through additional experience with the production process over time and through length of job tenure with a firm.

A detailed data set, described below, tracks movements of firm managers - in this case fishing captains - in and out of individual firms - in this case fishing vessels - that in turn allows identification of both the management and the more general firm effect and the time effect given a vector of inputs ${ }^{5}$. In short, our contribution distinguishes the management effect from the firm effect and the time effect through a three-way error components model using an unbalanced panel data set of three dimensions: management, firm, and time. The model is applied to 60 French tuna purseseine vessels harvesting in the Indian Ocean over the period 1980-2007, in which 159 unique skippers captained the vessels. The presence of more than one skipper managing a single firm (vessel) allows identification of the manager and firm effects.

We rigorously investigate the relative importance of the skipper and the vessel effects in fishing industries by drawing on three-way fixed effect models and variance decomposition and controlling for time and learning effects. The literature has previously only speculated on the difference between the effects of management and the other multiple unobserved factors that influence the firm's production, the firm effects. The literature has also given insufficient attention to both time-invariant and time-varying firm management and learning. Our results may have bearing on the public regulation of fishing industries by informing regulators of the relative importance of an unobserved input that essentially cannot be regulated, but which can potentially introduce important heterogeneity across firms (Kirkley et al., 1998, Pascoe and Coglan, 2002).

The rest of our paper is organized as follows. Section 2 discusses the firm's management of production in fisheries, skipper skill. Section 3 specifies the model and presents our estimation

\footnotetext{
${ }^{4}$ Horrace and Schnier (2010) review the time-varying technical inefficiency discussion in the stochastic production frontier literature, including parameterization of inefficiency into individual and time components, noting that prior to their work that a parametric specification of the evolving time varying technical inefficiency was necessary. Their work nonetheless cannot distinguish management from firm effects.

${ }^{5}$ We refer to the vessel as a firm for consistency with the broader management literature and to prevent confusion.
} 
strategy. Data are described in Section 4. Section 5 discusses the results. Finally, Section 6 provides concluding remarks.

\section{The firm's management of production in fishing industries}

The firm's management of production in fishing industries (skipper skill) is critical to the harvesting process and public regulation. Skipper skill may play a bigger part in this production process than in many other industries, because fish must be searched for, and only once found can the fish be caught. Fishing in many respects remains akin to an artisanal and hunting production process, with a premium on the skipper's very subjective skill set. As with artisan production and hunting, skipper skill is gained not by a formal process, but by innate ability and extensive experience while working very close to nature and its caprices.

The skilled skipper must have the ability to "read the sea" and its ecological environment, have good knowledge of the ocean, including its currents, depths, temperatures, and types of bottom, to accurately navigate to find the best grounds, to decide on where to search for fish, and to take calculated risks. Skipper skill is related to information gathering and utilization, managing and supervising the crew, managing a vessel and its machinery, gear, and equipment, interaction with the physical environment, and other factors.

Managerial effectiveness is also in part driven by product market competition and ownership through families or close social networks (Nickell, 1996, Syverson, 2004, Bloom and van Reenen, $2007)^{6}$. Tuna purse seiners, the firms that we investigate, operate within a globally integrated industry that is fiercely competitive because it produces standardized commodities and catches fish under regulated open access conditions. This product market competition leads to intense pressure on skippers to harvest as efficiently as possible, in turn creating incentives for managerial effort (Schmidt, 1997) and incentives for owners to retain only the most effective skippers ${ }^{7}$.

Globally, some tuna purse seine firms are family owned but without long lineages of family ownership, although multinational tuna processors, investment groups or private individual ship owners or co-owners own most vessels. Hence, the largely corporate ownership structure provides some moderate but nonetheless important pressures for efficient vessel management, and when there is skipper movement among vessels within the corporation knowledge spillovers and diffusion arise. Even in family-owned tuna firms, skippers beyond the founder's generation are not usually related to the owners, giving professional management, and suggesting selection based on ability rather than family ties and negating any Carnegie effects (Holtz-Eakin et al., 2003).

\footnotetext{
${ }^{6}$ Skippers and officers operating within the European tuna fleet originate from the same villages (respectively Concarneau in France and Bermeo in Spain).

${ }^{7}$ Syverson (2004) provides evidence that more competitive industries are associated with higher average productivity and lower productivity dispersion due to the selecting out of less productive firms.
} 
Although the presence of non-owner-operator skippers leads to the standard agency problem, this is countered by the contractual share system of remuneration and ready ability to gauge performance through close monitoring of landings and revenue after each fishing trip, and even during a trip due to logbooks that are filled out after every set of the net. Further, the share system of remuneration provides a contractual solution to obtaining optimal managerial effort to improve practices. The fierce product market competition and contractual practices mean that comparatively ineffective vessel management practices are unattractive to skippers and owners, even if there are costs to eliminating these practices.

Skipper skill is related to learning-by-doing following adoption of process innovations, associated with finding and catching fish, and learning-by-using, related to discovery of new and unanticipated uses of process innovations ${ }^{8}$. Learning-by-doing and -using, as disembodied technical change, shift the production frontier and will be captured by time effects and skipper experience as discussed below. The skipper effect over time, as a form of time-varying technical efficiency, includes the skipper's adoption and mastery of best practice technologies in each time period and thereby moving closer to the frontier that expands with technical change, i.e. "catching up" (or sometimes "falling behind" the expanding frontier). Invariably during fishing and for a given state of technology and input bundle, problems arise with handling of the net, positioning of the vessel, brailing, and other practices, and the ability to rapidly solve these problems contributes to technical efficiency gains. In a dynamic sense, skipper skill may be related to adopting investment-specific process innovations and the mastery implied by learning-by-doing and-using that shift out the best-practice production frontier.

Relationship-specific learning-by-doing refers to productivity increases that depend not only on a firm's general experience, but also on its joint experience with the particular firms with which it works (Kellogg, 2011) ${ }^{9}$. When two or more firms accumulate experience working together, relationship-specific intellectual capital is created that cannot be appropriated to relationships with other firms. This networking relationship can extend to code groups among skippers, in which vessels cooperatively search for fish and share information (and sometimes disinformation). If the relationship is broken, this capital is destroyed and productivity falls. Relationship-specific learning provides an incentive for skippers to cooperatively work with skippers and crew on other vessels with

\footnotetext{
${ }^{8}$ Learning-by-doing arises from increases in the stock of knowledge, independently of the characteristics of inputs used, and explains differences across vessels in the productivity of the same levels and types of inputs. It can be vessel and firmspecific and industry-wide, and captures routinization of tasks, organizational learning such as matching tasks with individuals, skipper learning, experience gained with electronics, finding fish, navigation, gear handling, and knowledge of the environment and resource conditions (currents, weather conditions, water temperature breaks, resource stock densities, etc).

${ }^{9}$ Relationship-specific learning-by-doing arises when the productivity improvements associated with the accumulation of experience are specific to not just an individual firm and manager, but to multiple firms working together in a vertical or horizontal contracting or broader relationship (Kellogg, 2011).
} 
which they have substantial experience, rather than those with which they have worked relatively little, which in our fleet is facilitated by the common village of skipper origin. Relationship-specific learning also offers an incentive for the corporation to retain skilled skippers and even to move them among vessels in order to foster networks and diffuse intellectual capital.

In the Indian Ocean tuna industry, mechanisms exist for learning along three dimensions: (1) producer-level corporate-specific learning (learning across vessels owned by a single firm that could occur, for example, through skipper movement across vessels along with overall corporate oversight); (2) vessel-level learning (an individual skipper and the crew on a vessel); and (3) relationship-specific learning between vessels working together, such as code groups, that can extend across corporations. Producer-specific learning (the first type) occurs because tuna corporations accumulate and learn from information as their vessels fish over time and space across the Indian Ocean. For example, the optimal selection of locations to fish in the Indian Ocean depends critically on the types of species and their abundance encountered throughout setting the net in different locations and times of the year and under different oceanographic conditions - and more recently impacted by Somali piracy. A tuna corporation's vessels collectively can fish before discovering the ideal locations and times via an educated trial-and-error process facilitated by embodied technical change and subsequent learning. Producers' learning is therefore technical in nature and tends to be both natural and physical capital stock, time, and location-specific

Skipper skill is also related to the actual implementation of work practices on fishing vessels. Learning on a vessel comes from improved teamwork and developments in crew members' skills. Some skippers may be better skilled at organizing and implementing work practices that are common to all fishing vessels. In this vein, Black and Lynch (2001) found when analyzing manufacturing plant data that it is not whether an employer adopts a particular work practice but rather how that work practice is actually implemented within the establishment that is associated with higher productivity. Involving crew in decisions about the organization of work may, for example, increase catch rates compared to more hierarchical management practices. This is a form of the second type of learning when the skipper, mates, mechanical engineer, and crew learn to improve these work practices over time and is representative of standard learning-by-doing in the literature.

Across many types of industries, recent production experience has a stronger impact on productivity than does older experience - forgetting effects (Argote et al., 1990). Given the centrality of skipper skill and learning to the fishing industry and the on-going investment-specific technical change in FADs and electronics and subsequent learning, coupled with continual responses to everchanging environmental and resource conditions, it is likely that a skipper's more recent experience in the Indian Ocean and on a vessel contributes to the importance of skipper skill, i.e. skipper skill can at least in part be time-varying (related to the first and second types of learning discussed above). 
To the best of our knowledge, the skipper (management) effect has so far not yet been analyzed in relation to other individual fixed effects such as the vessel (firm) and time effects and also in combination with time-varying management due to learning. Their combined power affects the intensity of fishing capacity, but the decomposition of the fixed effects in the variance of catches is far more interesting, by revealing the separate influence of environmental, technical change and behavioral patterns (choice of fishing techniques) behind these heterogeneity factors. We now discuss how a panel data set tracking multiple managers for each firm over time allows identifying the firm's management from firm and time effects in a production function using a three-way fixed effect model.

\section{Specification and estimation strategy}

To model the harvesting process of tuna purse seine vessels, we specify the output $Q_{i j t}$ of a skipper $i(i=1, \ldots, I)$ working on a vessel $j(j=1, \ldots, J)$ at time $t(t=1, \ldots, T)$ as the total catches of four tuna product categories, respectively skipjack (Katsuwonus pelamis), yellowfin (Thunnus albacares), bigeye (Thunnus obesus) and mix of young tunas of the aforementioned species. Tuna purse seine vessels can set their nets on either free swimming schools of tuna (mobile fish) or on tuna that has aggregated around drifting floating objects, including logs and Fish Aggregating Devices or FADs ${ }^{10}$. The latter dramatically reduces search costs and time (Campbell and Nicholl, 1994).

The input vector fishing effort is comprised of fishing time measured by the number of fishing hours $F H_{i j t}$, the total number of sets on floating objects $F A D_{i j t}$ and the total number of sets on free-swimming schools $F S_{i j t}$. Fishing hours represent variable inputs, a common specification in fisheries models where more detailed variable input information is unavailable (Kirkley et al., 1998). The number of sets on floating objects $(F A D)$ and free-swimming schools $(F S)$ captures the effort on each of the two ways to catch tuna by a purse-seiner.

We also introduce experience effects in the production function in order to account for learning-by-doing ${ }^{11}$. On the one hand, we capture the overall managerial experience by adding the total number of seasons that the skipper $i$ has been fishing in the Indian Ocean at date $t^{12}$. This skipper experience is denoted by $S E_{i t}$. Secondly, we include the number of seasons that the skipper $i$ has spent on the vessel $j$ at date $t$. This skipper vessel-specific experience $S V E_{i j t}$ measures the importance of job tenure in the fishing sense. By definition, overall managerial experience and job

\footnotetext{
${ }^{10}$ Fish Aggregating Devices are man-made floating objects (bamboo rafts) equipped with satellite tracking buoys. They increase tremendously the catchability of tuna, firstly by helping fishers to locate the fish and secondly by providing high successful set rates compared to those on free swimming schools (Campbell and Nicholl, 1994).

${ }^{11}$ See Kellog (2011) for a recent example of different experience variables capturing learning-by-doing.

${ }^{12}$ We have no information on the skipper's experience before managing a purse-seiner in the Indian Ocean. The skipper may have a longer experience by coming from another ocean, but he will nonetheless discover new fishing grounds and techniques and therefore can be considered as an inexperienced manager when he joins the Indian Ocean fleet.
} 
tenure are potentially correlated : the two measures are for instance equal when the captain always stays on the same vessel. Specifying a Cobb-Douglas technology gives ${ }^{13}$ :

$$
Q_{i j t}=A * F H_{i j t}{ }^{\alpha}{ }_{F H} * F A D_{i j t}{ }^{\alpha}{ }^{\alpha A D} * F S_{i j t}{ }^{\alpha_{F S}} * S E_{i t}{ }^{\alpha}{ }_{S E} * S V E_{i j t}{ }^{\alpha}{ }^{\alpha V E}
$$

where $A$ denotes the intercept and the $\alpha_{k}(k=F H, F A D, F S, S E, S V E)$ are parameters to be estimated. Taking logs gives:

$$
\begin{aligned}
\ln Q_{i j t}= & \ln A+\alpha_{F H} \ln F H_{i j t}+\alpha_{F A D} \ln F A D_{i j t}+\alpha_{F S} \ln F S_{i j t} \\
& +\alpha_{S E} \ln S E_{i t}+\alpha_{S V E} \ln S V E_{i j t}
\end{aligned}
$$

Compared to conventional production functions, it should be noted that our framework does not include capital stock as an input. This does not mean that we neglect the role of capital in our specification. We treat the time-invariant capital stock measures as a heterogeneity term in our empirical analysis, so that capital stock will be swept away when turning to a fixed effect estimation

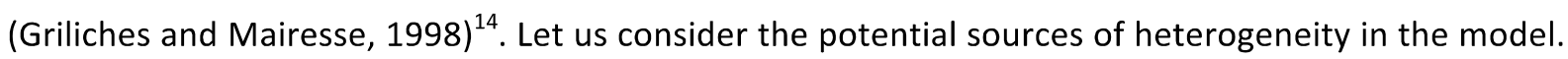
Vessel effects, skipper effects, and time effects can explain differences in vessels' catches.

Vessel effects include the capital stock, which can be measured by several time-invariant variables such as vessel size (gross tonnage, power or length), capacity (fish wells) or process innovations embodied in the capital stock that allow fish detection on board (binoculars, sonars, echosounders, bird radars). Skipper effects are related to knowledge of fishing sites, intuition to find the densely populated areas of fishing, social links with other skippers, capability of manœuvring the vessel around the moving free schools, ability to analyze environmental data from various electronic devices (chlorophyll concentration, sea currents, bird spots, sea surface temperature), choice of fishing techniques, risk attitudes (following the rest of the fleet or fishing alone) or management of the crew. Most of these features vary over time and should depend on the skipper experience, but it could also be argued that skipper skills are innate (a belief which some within the industry hold). Insignificant experience variables but significant fixed effects would provide evidence confirming this view.

Time effects capture the parts of the Solow residual that is not picked up by the vessel and skipper effects. The time heterogeneity term includes in particular disembodied and embodied technical change (Hulten, 1992). Technical change includes learning-by-doing and -using as forms of disembodied technical change and investment-specific or embodied technical change. Embodied technical change captures quality differentials between vintages of capital over time (changes in technical efficiency associated with changes in vintages of capital) and differs from capital-

\footnotetext{
${ }^{13}$ A Cobb-Douglas specification rather than a translog limits the multicollinearity that could potentially plague our analysis and as compared to a strict linear specification allows production coefficients to be interpreted as production elasticities.

${ }^{14}$ We have also attempted to estimate a production function with an additional input measuring capital services, defined as days at sea by vessel capacity. However, the log of this input is strongly correlated with the log of fishing hours, with an elasticity equal to $0.834\left(R^{2}=0.831\right)$. We thus do not account for capital services in our regressions to avoid multicollinearity problems. Moreover, specifying capital as a stock or flow of services is not a clear-cut issue (Mundlak, 2001).
} 
augmenting technical change ${ }^{15}$. Also, the time-specific effect picks up changes in the resource stocks' biomass and accessibility (Squires, 1992), changes in the state of the environment and habitat of fish (including the mixed layer depth, El Niño Southern Oscillations -ENSO- events, ocean and weather conditions independent of ENSO events) as well as prey episodes such as the proliferation of Natosquilla investigatoris between 2003 and 2005 (Potier et al., 2007).

In what follows, we denote the unobserved heterogeneity terms respectively by $\theta_{j}$ for vessels and $\delta_{i}$ for skippers, while $\gamma_{t}$ corresponds to the unobserved time effect. The econometric model we want to estimate is therefore specified as a Cobb-Douglas production function:

$$
\begin{aligned}
\ln Q_{i j t}= & \ln A+\alpha_{F H} \ln F H_{i j t}+\alpha_{F A D} \ln F A D_{i j t}+\alpha_{F S} \ln F S_{i j t} \\
& +\alpha_{S E} \ln S E_{i t}+\alpha_{S V E} \ln S V E_{i j t}+\theta_{j}+\delta_{i}+\gamma_{t}+\varepsilon_{i j t}
\end{aligned}
$$

with $\varepsilon_{i j t}$ a residual error term supposed to be uncorrelated with the selected explanatory variables. As the various specific error terms are likely to be correlated with each other and with any of the observable inputs, we rely on a fixed-effect framework.

Let us give a few examples of possible correlation between the various unobserved heterogeneity terms and the covariates. Skippers may have very different attitudes with respect to risk, and this unobservable characteristic will be picked up by the individual effect $\delta_{i}$. At the same time, it may certainly be correlated with both $F A D_{i j t}$ and $F S_{i j t}$ if a fishing technique based on freeswimming schools is perceived as a more risky one ${ }^{16}$. It may also be correlated with fishing effort if a more risk-averse skipper decides to spend less time searching for fish and prefers to spend more time fishing. Also, depending on their fishing fittings, some vessels may be more suitable to the use of FADs, which would lead to some correlation between the vessel fixed effect $\theta_{j}$ and the covariates $F A D_{i j t}$ and $F S_{i j t}$. In particular, larger vessels are more likely to use FADs than smaller ones (Guillotreau et al., 2011).

Since there are three sets of fixed effect parameters, the linear specification (3) defines a three-way error components model. At that stage, it is important to note that each of the three dimensions (vessels, skippers, time) can move with respect to the others, making possible the identification of the three effects respectively ${ }^{17}$. To estimate such model, we rely on the framework

\footnotetext{
${ }^{15}$ In the present case of the French purse-seine tuna fleet, it may include the amount of investment in hand-made FADs (number, materials, design) and radio or satellite buoys made over different years. Nets also have electronic sensors to assess currents and depth to optimize net tow. In fact, investment in gear and equipment (capturing embodied technical change) predominates over investment in vessels in this fishery and most other industrial fisheries.

${ }^{16}$ The proportion of positive sets is about $90 \%$ for FAD fishing, but only 50\% for free school fishing (Campbell and Nicholl, 1994).

${ }^{17}$ A few other papers have added a third dimension to a panel, but this third dimension is often linked with the two others. For instance, two dimensions can be both related to time (different sub-periods within a set of larger periods considered) or space (country/city of origin and destination in a trade-flow model). Recently, a three-way fixed effects model was estimated in the context of fisheries by combining 12 vessels over 3 years and 44 fishing zones (Horrace and Schnier, 2010). The third effect was space rather than skipper, and identification was allowed by specifying biomass as an exogenous exponent parameter in a Cobb-Douglas production technology.
} 
developed in Abowd et al. (1999), who investigated the analysis of data with three dimensions of variation in the context of longitudinal employer-employee data. Before presenting our estimation strategy, let us briefly explain the two main difficulties faced when estimating equation (3).

First, there is a problem of dimensionality in the general case. Consider a panel data model with two dimensions, say $i$ (individual) and $t$ (time). It is well known that there are two ways to estimate such fixed effect models. The first one consists in adding into a linear regression a set of individual dummies whose coefficients are simply the fixed effects. The second one consists in using a within transformation (time-demeaning). When the number of individuals is large, it is not possible to estimate the augmented linear model including the individual dummy variables, thereby requiring the within transformation. With a three way error-components model, it is not possible to rely on specific-dummies for the three levels of units when there are large samples of observations: there would be too many variables on the right-hand side of the regression. As suggested by Abowd et al. (1999), equation (3) can in fact be reduced to a two-way error-components model, since the time dimension of the panel is short. It is therefore straightforward to estimate the unobserved time component through the use of time dummies ${ }^{18}$.

Second, there is the issue of identification of the different unobserved heterogeneity terms. In the general case, is it possible to disentangle the skipper (management) effect from the vessel (firm) effect? Suppose that skippers always work on the same vessels over the period (giving a nested case). Then, the vessel effect would be perfectly confounded with the skipper effect and there would be only one heterogeneity term for each vessel-skipper combination, absorbing both $\delta_{i}$ and $\theta_{j}$. Now, suppose that we have data on skippers changing of vessels one or several times during the period under consideration. We refer to these skippers as movers, by contrast with skippers working always on the same vessels (non-movers). Then, there would be some variations in the vessel dummies for these skippers, and the specific-vessel effects $\theta_{j}$ would be separately identified from the specificskipper effects $\delta_{i}$. In fact, both sets of fixed effects $\delta_{i}$ and $\theta_{j}$ will be more precisely identified with substantial changes in the mix of skippers and vessels over time.

We now present our estimation strategy. Suppose first that we are interested in obtaining unbiased (net of unobserved heterogeneity) estimates of $\alpha_{F H}, \alpha_{F A D}, \alpha_{F S}, \alpha_{S E}$ and $\alpha_{S V E}$, without recovering the decomposition between $\delta_{i}$ and $\theta_{j}$. Let us index by $c$ each skipper-vessel combination $(i, j)$ and let $\tau_{c}=\theta_{j}+\delta_{i}$ be a specific component absorbing the effect of both the skipper and the vessel. Then, elasticities of inputs may be obtained from the following within transformation:

$$
\ln Q_{i j t}-\overline{\ln Q_{l \jmath t, c}}=\sum_{k} \alpha_{k}\left(\ln X_{k, i j t}-\overline{\ln X_{k, c}}\right)+\left(\varepsilon_{i j t}-\overline{\varepsilon_{l \jmath t, c}}\right)
$$

\footnotetext{
${ }^{18}$ However, it is not possible to turn to a within transformation for the two remaining dimensions $i$ and $j$ because skippers and vessels are not necessarily nested, which is the case in our context since some skippers work on different vessels at different points in time.
} 
where $X_{k}$ refers to the selected covariates, a set of time dummies being included. Since by construction each $c$ denotes a unique skipper-vessel combination, then the matched heterogeneity term $\tau_{c}$ drops from the regression given the within transformation. One can also obtain the values of the matched effects $\tau_{c}$ by adding a set of dummies $M_{c}=1$ when $c=i, j$ (and $M_{c}=0$ otherwise) constructed from each skipper-vessel combination in the linear model such that:

$$
\ln Q_{i j t}=\sum_{k} \alpha_{k} \ln X_{k, i j t}+\sum_{c} \tau_{c} M_{c}+\varepsilon_{i j t}
$$

However, there is no way from $\tau_{c}$ to recover both $\delta_{i}$ and $\theta_{j}$. To obtain separate estimates for $\delta_{i}$ and $\theta_{j}$, we follow the strategy developed in Abowd et al. (1999) and estimate a within regression that sweeps out the skipper-specific component. We control for vessel unobserved heterogeneity by adding a set of dummy specific-vessel variables. We hence estimate:

$$
\ln Q_{i j t}-\overline{\ln Q_{l j t, l}}=\sum_{k} \alpha_{k}\left(\ln X_{k, i j t}-\overline{\ln X_{k, l}}\right)+\sum_{j} \theta_{j}\left(V_{j, i t}-\bar{V}_{j, i}\right)+\left(\varepsilon_{i j t}-\overline{\varepsilon_{l j t, l}}\right)
$$

where $V_{j, i t}$ are dummy variables for vessels such that $V_{j, i t}=1$ for vessel $j$ and $V_{j, i t}=0$ otherwise. When a skipper $i$ always works on the same vessel $j$, we then have $V_{j, i t}=\bar{V}_{j, i}$. As a consequence, it is not possible to estimate the vessel effect $\theta_{j}$ in that case. Thus, this discussion makes clear that the vessel-specific term $\theta_{j}$ is identified only for vessels managed by more than one skipper over time. Conversely, the parameters $\alpha_{k}$ associated with the (observable) explanatory variables are identified using information from both movers and non-movers.

A crucial feature is that identification of vessel effects is possible only within a group, defined as a set of observations within which there is skipper mobility, but between which there is no mobility (Abowd et al., 1999, Andrews et al., 2006). Within each group, there is always one vessel effect that has to be taken as the reference, the other vessel effects being expressed as differences from the reference. As a consequence, some normalization of the fixed effects is required between the various groups. A simple solution consists of subtracting for each observation the mean of the fixed effects of the corresponding group. As a final step, we perform a variance decomposition analysis to assess the respective weights of the skipper, vessel and time heterogeneity factors.

\section{Description of the data}

Our empirical analysis is based on a dataset collected by the Observatoire thonier (IRD, France), which covers the entire history of the French purse-seine fishery in the Indian Ocean since its inception in 1980 to 2007 (28 years). The data concern tuna caught by 159 French skippers and 60 vessels in total. They include the tonnage catches of four tuna categories: yellowfin, skipjack, bigeye and mix of young tunas of the aforementioned species. Each observation in our sample corresponds to a combination of one skipper, one vessel and one fishing year. Following this definition, our sample comprises 1,197 observations corresponding to 320 matched skipper-vessel combinations. 
The mean number of fishing seasons per skipper is equal to 7.5. The proportion of skippers having completed only one fishing season is around 10 percent, while more than half of them (54.7\%) have managed at least 5 fishing seasons. As emphasized in the previous section, some mobility of skippers on vessels is required to disentangle the skipper- and vessel-specific components. We represent the number of skippers per vessel in Figure 1. On average, 5.3 different skippers managed each vessel over the selected period. Only 3 of the 60 vessels (5\%) were always managed by the same skipper, $20 \%$ by two different skippers and $38.4 \%$ by more than 5 skippers. At the skipper level, 77 of them (48.4\%) have managed only one vessel and $51.2 \%$ have completed their fishing seasons worked on more than one vessel. The proportion of movers, defined as skippers that change of vessel over time, is thus much more important at the vessel-skipper-year level (76.3\%).

Insert Figure 1 here

It is interesting to illustrate the mobility of skippers across vessels and time for a few selected observations. Consider first skipper $A^{19}$. This is the case of a non-mover skipper since he has completed 7 fishing years with the same vessel. Skipper B has managed three different vessels. He began working on vessel $n^{\circ} 2$ from 1991 to 1997 , then on vessel $n^{\circ} 3$ from 1997 to 2005, and finally on vessel $n^{\circ} 4$ afterwards. Skipper $C$ has first managed vessel $n^{\circ} 8$, and then captained vessel $n^{\circ} 2$, which was before managed by skipper B. Skipper D has managed four different vessels from 1997 to 2007 $\left(n^{\circ} 6, n^{\circ} 5, n^{\circ} 3, n^{\circ} 7\right)$, one of them being the $n^{\circ} 3$ after the departure of skipper $B$. To summarize, our data includes a large proportion of movers, meaning that it is possible to identify both the skipper and vessel fixed effects within a panel data specification.

Table 1 summarizes the variables of interest for our empirical analysis. We observe some substantial differences between non-moving and moving skippers. The average catch per vessel, skipper and year is $15.3 \%$ higher for the latter group, respectively 1,308 tons for movers instead of 1,122 tons for non-movers. A simple explanation of this gap could be due to the fact that movers are characterized by a fishing effort (measured in hours) that is $4.7 \%$ higher. The average number of fishing sets on floating objects (26) is lower than the number of sets on free-swimming schools (32), a pattern that is found both for movers and non-movers. Also, movers are much more experienced than non-movers (7.3 fishing seasons on average against 4.1).

\section{Insert Table 1 here}

As shown in Figure 2, total catches of the whole fleet have significantly increased over the period, particularly after 1998, when new and bigger boats joined the fleet. As a consequence, annual total catches increased from an average 75,000 tons to more than 100,000 tons (IOTC, 2006). The composition by species has also changed throughout the period. Some years were more

\footnotetext{
${ }^{19}$ We preserve anonymity of both skippers and vessels in this description of mobility.
} 
favorable to skipjack catches (late 1990s) and others to large yellowfin catches (1988, mid-2000s). Explanations are mainly related to environmental conditions as well as to the increasing use of artificial FADs (Potier et al., 2007, Miyake et al., 2010).

\section{Insert Figure 2}

Figure 2 also shows substantial variation in the use of FAD sets over the period. They increased from $42 \%$ for the first-half of the period (1984-1995) to $49 \%$ for the second half (19962007), mainly because of the increasing investment in radio and satellite buoys on FADs (Miyake et al., 2010, Guillotreau et al., 2011). This trend may be seen as a form of embodied technical change. For some exceptional years such as 1997-98, catches of skipjack and mixed tuna around FADs were particularly high because the mixed layer (limit in depth between warm and cold sea temperatures) had deepened in the west Indian Ocean due to a strong El Niño episode and the fleet had to move eastward and use more FADs to catch tuna. An opposite situation occurred between 2003 and 2005. Big schools of large yellowfin tuna rose near to the surface to feed on the abundant squilla shoals and were made then more accessible to purse-seiners without using FADs (Ménard et al., 2007, Potier et al., 2007).

\section{Econometric results}

\subsection{The role of managerial ability}

We investigate the determinants of tuna catches in Table 2. The total catch of the four major tuna product categories is expressed as a linear function of number of fishing hours, number of FAD sets, number of sets on free-swimming schools, skipper experience and skipper vessel-specific experience. Since the Cobb-Douglas production function uses the log of both the dependent and explanatory variables, the regression coefficients are simply elasticities. We also introduce a set of year-specific dummies into each regression.

\section{Insert Table 2 here}

Estimates from the model with both vessel and skipper fixed effects are in column 1 . We rely on a within transformation with respect to each skipper in order to sweep out the skipper heterogeneity and add in the regression a set of vessel dummies. We note that both the selected covariates and the time effects explain around $90 \%$ of the variations in total harvest $\left(R^{2}=0.903\right)$, meaning that our specification fits the data well. An increase of 1 percent in the number of hours spent fishing increases the harvest by $0.37 \%$. Catches are positively correlated with both the numbers of sets on floating objects and sets on free-swimming schools. That more sets results in higher yields is of course an expected result, but we also note that the sensitivity of catches to FAD 
fishing is nearly twice that of free schools. A Wald test shows that both coefficients are significantly different at the 1 percent level ${ }^{20}$.

Our data thus show that the use of FADs is more efficient than free schools to improve tuna catches. In turn, this has a direct effect on the composition of fish caught (Campbell and Nicholl, 1994). For that purpose, we have estimated specific fixed effect regressions for the four types of tropical tunas. Our results, not reported, are twofold ${ }^{21}$. On the one hand, the number of sets on floating objects is significant only for skipjack, bigeye and mixed of young tunas, the catch-FAD elasticities being respectively equal to $0.98,0.63$ and 0.66 . On the other hand, the correlation between the number of sets on free-swimming schools and catches is only significant for large yellowfin (with an elasticity of 0.91$)^{22}$. It follows that the variety of tuna caught strongly depends on the fishing techniques (Campbell and Nicholl 1994, Guillotreau et al. 2011). Skippers fishing on free schools will essentially catch yellowfin tunas, while those fishing on FADs will essentially catch the three other tuna product categories.

We also take into account the overall skipper experience and fishing job tenure that reflect learning. We find very low values for the associated coefficients and none of the experience covariates are statistically significant in the three-way fixed effect model. Furthermore, an F-test allows us to reject the joint significance of the two experience variables, with a statistic equal to 0.15 $(p=0.863)$. This is an important result related to the degree to which managerial ability changes over time. Indeed, we account for two components of managerial ability net of the role played by the vessels' characteristics. The first component, picked up by the skipper fixed effect, is time-invariant. The second potentially increases with time through learning by doing, and is the sum of the tenure and overall experience of the skipper. Our two-way fixed effect estimates clearly lead to the conclusion that managerial ability is essentially time-invariant as in the original framework of Mundlak (1961).

However, it could be argued that the experience coefficients are not significant because of a multicollinearity problem. Indeed, overall experience and vessel-specific experience are strongly correlated in our data set, with a coefficient of correlation around 0.5. As sensitivity analysis, we estimate two fixed effect regressions separately with only one experience variable at a time. We obtain elasticity coefficients equal to $0.012(t=0.26)$ for overall experience and equal to $-0.007(t=-$

\footnotetext{
${ }^{20}$ As there have been changes in the use of FAD sets over time (as shown in Figure 2), we have also estimated a fixed effect model with two additional crossed terms corresponding to the product of the number of sets on floating objects / on freeswimming schools times a dummy variable equal to one after 1989. Both crossed terms are not statistically significant, meaning that the elasticity of sets on floating objects / on free-swimming schools has not changed respectively before and after 1989.

${ }^{21}$ All our additional results are in an appendix available upon request from the authors.

${ }^{22}$ We find a positive correlation between the number of sets on FADs and yellowfin. The corresponding elasticity is equal to 0.133 , with a t-value equal to 1.40
} 
0.28) for job tenure, which are very close to our previous estimates. These results clearly show that the lack of significance of experience on tuna catches does not stem from multicollinearity.

Figure 3 represents the time profile of tuna captures net of the role played by both observed and unobserved vessel and skipper heterogeneity. To a large extent, the time effect captures environmental variability already described above in terms of El Niño-Southern Oscillations (warmer sea surface temperatures occurring every few years, 3 to 7 years according to Marsac and Le Blanc, 1999) and of Indian Ocean zonal dipole mode that is a basin-scale pattern of surface and sub-surface temperature affecting the Indian ocean (Meyers et al., 2007). Also, severe mixed layer depth (MLD) anomalies that are known to reduce catchability of tuna may be seen in Figure 3, respectively in late/early 1991-1992, 1997-1998 and 2006-2007.

\section{Insert Figure 3}

Conversely, in spite of moderate warming between 2003 and 2005, the MLD anomaly in that period was not a deepening but a shoaling, and catches reached historical high scores between 2003 and 2005, explaining the second peak of the time effect in 2003-2004. As far as the first peak of 1988 is concerned, the Scientific Committee of the Indian Ocean Tuna Commission reported exceptionally high catches of yellowfin tuna in 1988 (54,149 tons), surrounded by two moderate years (37,118 tons in 1987 and 38,411 tons in 1989). For skipjack, 1988 does not represent such an anomalous year, suggesting that the same shoaling of the mixed layer depth may have happened.

Estimates from the three-way error component model allow us to perform a variance decomposition and to assess the role played by the various heterogeneity terms. The selected covariates play a major role as they explain $72.3 \%$ of variations in total catches of tuna (Table 3, column 1). The skipper and vessel fixed effects have a rather similar influence, respectively $5.7 \%$ and $5.1 \%$, and they have more influence than the year fixed effect $(2.7 \%)$. Comparing the relative contribution of experience (defined as the sum of tenure and overall experience) and the timeinvariant skipper effect to total managerial ability indicates that only $0.3 \%$ of the manager contribution is due to its time-varying component.

\section{Insert Table 3 here}

A close look at the different covariance terms is illuminating. In particular, both skipper and vessel effects are expected to be related to the input variables if we consider for instance that some skippers have a preference for either FADs or free schools. The covariance between inputs and vessel fixed effects amounts to $9.4 \%$ of the total decomposition. A simple explanation is that some vessels are more adapted for one of the two techniques or are more suitable for extended fishing time, thereby constraining the skipper's fishing decisions ${ }^{23}$. Overall, the fact that the contribution of the

\footnotetext{
${ }^{23}$ Conversely, the covariance term between inputs and the skipper fixed effects is negative and of small magnitude (-1.2\%).
} 
different covariance terms is substantial brings support to our fixed effect specification. Otherwise, there would have been no correlation between the vessel and skipper unobserved components and the selected covariates.

The time effect can also be partly affected by the presence of the vessel effect and the selected inputs. We hypothesized that the time fixed effects may capture a change of environmental conditions, including changes in resource abundance and distribution, as well as disembodied and embodied technical change (Hulten, 1992, Squires, 1992). The increasing size of vessels joining the fleet over the period requires (and allows) higher yields per fishing set to realize scale and scope economies. Hence, it is more likely to drive skippers toward FAD fishing rather than fishing on free schools because this former technique allows a higher frequency and a higher success rate of fishing sets than the latter (Miyake et al., 2010, Guillotreau et al., 2011). Our results clearly show FAD fishing increases more effectively than free schools the catch levels in all circumstances, conferring the scope and scale economies. However, we find little interaction between the year fixed effects and either the inputs or vessel/skipper fixed effects. Finally, the covariance term between the skipper and vessel fixed effects is negative (-5.3\%). We will return to this puzzling finding later.

\subsection{Additional results}

\section{Vessel fixed effect and vessel's characteristics}

To scrutinize the role of firm's management and disentangle it from a pure capital effect, we study the factors influencing the vessel fixed effects. By construction, all the observed and unobserved variables invariant at the vessel level are picked up by the vessel fixed effect. For instance, stock factors such as vessel size, engine power or storage capacity are included in $\theta_{j}$. With detailed information on vessel's characteristics, it is possible to perform a post-estimation analysis of the vessel-specific component. For that purpose, we match our data on tuna catches with a data set covering the French tuna fleet, with information on year built (to capture potential vintage effects), vessel length (in meters), engine power (in $\mathrm{kW}$ ), and storage capacity (fish wells in $\mathrm{m}^{3}$ ).

We estimate a linear regression at the vessel level of the form $\theta_{j}=Z_{j} \eta+\zeta_{j}$ using OLS, with $Z_{j}$ a set of vessel-specific characteristics, $\eta$ a vector of coefficients to estimate, and $\zeta_{j}$ an error term. As the vessel fixed effects are not identified for 6 vessels (the ones with non-moving skippers), our sample includes 54 observations. Given the high collinearity in vessel characteristics (for instance between vessel length and storage capacity), we only account for the $\log$ of storage capacity $\left(\ln S C_{j}\right)$ and year of construction of the vessel $\left(Y C_{j}\right)$ as covariates. We obtain $\theta_{j}=-12.777+0.005 * Y C_{j}+$ $0.418 * \ln S C_{j}$, but only storage capacity is significant at the 5 percent level (with $\mathrm{t}=2.12$ ). An 
explanation of the insignificant coefficient for year of construction could be the progressive incorporation of new technologies on vessels that make older vessels as efficient as newer ones ${ }^{24}$.

That larger purse-seiners catch more fish on average has been well understood by the ship owners since the proportion of French purse-seiners whose gross registered tonnage is greater than 800 tons has increased from $43 \%$ in the 1980 s up to $90 \%$ in the late 2000 s (www.iotc.org). This increasing trend of capacity, which is captured by the vessel fixed effect, does not appear in the time fixed effect. This would tend to confirm the key role of investment and potential increasing returns to scale in the fishing capacity.

\section{Movers versus non-movers}

As made clear when presenting our estimation strategy, the mobility of skippers is a central issue in our empirical analysis. It is hence interesting to contrast the behavior of movers and nonmovers. By definition, the moving decision is a skipper-specific covariate, so that we cannot add this explanatory variable in the three-way fixed effect model: it is simply picked up by the skipper fixed effect. As a consequence, we choose to estimate separate regressions for movers (skippers managing different vessels over the period) and non-movers (skippers always managing the same vessel). In the latter case, we note that the vessel fixed effects are not identified ${ }^{25}$.

As shown in Table 2 (columns 2 and 3), we find different coefficients for the number of sets on floating objects for movers and non-movers. For non-movers, tuna catches are indifferently affected by the number of sets on FADs and free schools (the elasticity is around .27-.29 for the two techniques), but this is not the case for movers. For them, the FAD elasticity is more than twice as high compared to the free school elasticity ( 0.49 against 0.21 ) and a Wald test shows that the null hypothesis of identical coefficients is rejected at the $1 \%$ level. This could mean that a change of vessel makes skippers use FADs more intensively to increase the level of catches, whatever anterior preferences for one technique or the other. Again, none of the time-varying experience covariates are significant in the fixed effect regressions ${ }^{26}$.

Results from the variance decomposition lead to some differences between movers and nonmovers (columns 2 and 3, Table 3). Among the former, the vessel and skipper unobserved terms

\footnotetext{
${ }^{24}$ These investment-specific process innovations are predominately electronics (e.g. bird radar, computers, echo sounders) and FADs (themselves increasingly with embedded electronics such as GPS and sonar) rather than the vessel hull (which embodies the state of design and materials technology at the time of construction). Owners and skippers simply add electronics and FADs to a vessel, i.e. these process innovations are not dependent upon the particular technology embodied in hull and vessel design and size or whether a skipper is a mover or not, the skipper's length of tenure, or vessel's age, and are comparatively inexpensive. These innovations rapidly diffuse through the fleet for a variety of reasons, including skipper movement. Further, there are no appreciable differences in skipper search skills and use of IT equipment between newer and older vessels.

${ }^{25}$ The fixed effects introduced in this regression encompass both the vessel and skipper heterogeneity terms.

${ }^{26}$ Tenure and overall experience are by definition equal among non-movers, since all the fishing seasons in the Indian Ocean have been completed on the same vessel.
} 
amounts to $4.6 \%$ and $3.7 \%$ respectively. The covariance term is the highest for inputs and vessel fixed effects (8.6\%). Concerning non-movers, the role of inputs when explaining tuna catches is lower (60.3\% instead of $71.5 \%$ for movers). The role played by the vessel fixed effect is higher $(9.5 \%)$, but it encompasses both the unobserved heterogeneity related to the vessel and the skipper. The fact that the variance decomposition of the overall sample shows a higher skipper effect $(5.7 \%)$ than on the mover sample (3.7\%) suggests that the skipper effect matters even more for non-movers: the latter use less FADs and their catches depend more on their own skills than equipment.

This result also suggests that there are not any expected gains from relationship learning when corporate production requires coordinated inputs from multiple firms (vessels), to the extent productivity is a function of not just each skipper's individual experience on a particular vessel but also the corporate joint experience when that is obtained by skipper movement between vessels (as opposed to more hierarchical corporate management) ${ }^{27}$.

\subsection{Robustness checks}

\section{Sensitivity to specification}

We now attempt to assess the robustness of our empirical findings. A first concern is the parameterization of the production function given the lack of flexibility of the Cobb-Douglas equation. We thus estimate respectively a linear specification $Q_{i j t}=\sum_{k} \alpha_{k} X_{k}+\theta_{j}+\delta_{i}+\gamma_{t}+\varepsilon_{i j t}$ and a quadratic specification $Q_{i j t}=\sum_{k} \alpha_{k} X_{k}+\sum_{k} \sum_{l} \beta_{k} X_{k} X_{l}+\theta_{j}+\delta_{i}+\gamma_{t}+\varepsilon_{i j t}$. These new estimates, not reported but available upon request, confirm our previous conclusions.

First, total tuna catches are much more sensitive to the number of sets on floating objects than to the number of sets on free-swimming schools. Secondly, the time-varying experience variables are not significant in the linear production function ${ }^{28}$. Thirdly, we find a slightly higher weight for the invariant managerial ability term when implementing the variance decomposition with the linear specification. The only change lies in the role played by the time fixed effects, which is now around $8 \%$. Conversely, the contribution of the selected inputs is about $10 \%$ lower $(62.9 \%$ against $72.3 \%)$. Whatsoever, our results are not sensitive to the form of the production function.

A second concern is related to the way we take unobserved heterogeneity into account. Clearly, our contribution separates the vessel effects from the skipper effects. It seems important to know whether the inclusion of fixed effects affects or not the coefficients of the selected inputs.

\footnotetext{
${ }^{27}$ Because our data precludes information on skipper code groups, i.e. inter-vessel cooperation in searching for fish, we cannot conclude on that type of networking effect, which in part comprises relationship learning-by-doing. Hence, we cannot comment on whether skippers tend to choose an informal contractual form that increases cross-vessel personal contacts when they anticipate working together for an extended period of time (a situation in which maximizing the rate of relationship-specific learning is particularly important).

${ }^{28}$ We find a negative coefficient (at the 10 percent level) for overall experience in the quadratic specification, while the product of fishing hours times overall experience is positively correlated to total catches.
} 
Going back to the Cobb-Douglas function, there are three alternative ways to account for unobserved heterogeneity compared to our specification (3). A first possibility is to include a vessel fixed effect and to neglect the skipper effect, i.e. $\ln Q_{i j t}=\sum_{k} \alpha_{k} \ln X_{k}+\theta_{j}+\gamma_{t}+\varepsilon_{i j t}$. A second, symmetric scenario consists in adding a skipper fixed effect of the form $\ln Q_{i j t}=\sum_{k} \alpha_{k} \ln X_{k}+\delta_{i}+\gamma_{t}+\varepsilon_{i j t}$, which leaves aside the potential influence of the vessel characteristics. The third possibility, already discussed, is to add a matched skipper-vessel fixed effect so that the corresponding specification is $\ln Q_{i j t}=\sum_{k} \alpha_{k} \ln X_{k}+\tau_{c}+\gamma_{t}+\varepsilon_{i j t}$.

We notice several interesting differences when comparing the various sets of fixed effects estimates (not reported, but available upon request). First, the elasticities of fishing effort (fishing hours and number of sets) are rather similar with either vessel fixed effects, vessel-skipper fixed effects or skipper fixed effects. The elasticity of fishing hours ranges from 0.37 to 0.47 and total catches are much more sensitive to sets on floating objects than to sets on free-swimming schools. Secondly, the fishing hours coefficient is much lower with the skipper fixed effect specification. By definition, the vessels' characteristics are expected to influence the number of fishing hours (through the wells capacity or fuel autonomy for instance), so that the impact of the fishing effort on catches is underestimated when neglecting the vessel unobserved heterogeneity.

Thirdly, the two measures of experience are never significant except for the model with the matched vessel-skipper component. For the matched specification, tuna catches significantly increase with the total number of fishing seasons that the skipper has spent fishing in the Indian Ocean, while the captain's success is negatively affected by experience with a particular vessel. This negative correlation between tuna catches and the skipper vessel-specific experience goes against the idea of an on-the-boat learning-by-doing process $^{29}$, but these findings should be interpreted with caution. Indeed, the matched effect may be correlated with the vessel-specific experience. If the mobility of skippers is related to a poor match, then the skipper vessel-specific experience will be mechanically very low and job tenure would be endogenous in the fixed effect regression ${ }^{30}$.

Although we observe that separating the vessel component from the skipper component does not substantially affect the coefficients associated with fishing inputs (which is in itself a result), the three-way model remains nonetheless necessary to analyze total managerial ability.

\section{Endogeneity and selection issues}

So far, we have assumed that the various inputs were exogenous when estimating the CobbDouglas production function. A difficulty is that the skipper may have some knowledge on the

\footnotetext{
${ }^{29}$ Corresponding to the second type of Kellog's typology applied to fisheries seen in section 2.

${ }^{30}$ We have also estimated the matched fixed effect model with only one measure of the skipper experience. We find a positive coefficient (significant at the 10 percent level) for the skipper overall experience, while the coefficient is negative but not significant ( $t=-1.01$ ) for the skipper vessel-specific experience.
} 
unobserved productivity when making the input choices, so that the fishing decisions would be correlated with the unobserved heterogeneity term (simultaneity problem).

In the fixed effect specification originally proposed by Mundlak (1961) and Mundlak and Hoch (1965), the unobserved productivity term may be decomposed into one firm-specific timeinvariant effect and one idiosyncratic shock. The two following assumptions are necessary for the fixed effect estimator to be consistent. First, the idiosyncratic shock is realized after the firm makes its decisions on inputs. Secondly, there is no serial correlation in these shocks. A well-known result is that the within estimator is expected to provide very small estimates of the elasticity of production factors when these two conditions do not hold (Griliches and Mairesse 1998).

As pointed out in Olley and Pakes (1996) and Levinsohn and Petrin (2003), these two conditions are not likely to hold in the manufacturing sector where capital is accumulated through some deterministic dynamic investment process. These authors have suggested overcoming the endogeneity problem by using observed input decisions to control for unobserved productivity shocks, either investment or intermediate inputs being used as proxy for productivity shocks ${ }^{31}$. However, the situation seems somewhat different for fisheries. The idiosyncratic shock in tuna harvesting may be interpreted as any random and unpredictable shock that vessels will face during their fishing trip, such as weather (storm, rainfall, heavy swell, etc.), fishing gear or engine breakdown, or availability and density of groups of tuna. Also, a successful fishing day may be followed by a period of poor catches, meaning that the unobserved productivity is on a priori grounds less subject to serial correlation.

To assess whether endogeneity is a problem in our specification, we proceed in the following way. We assume that choices of fishing hours, sets on floating objects, and sets on free-swimming schools are inputs that may be potentially endogenous (in that they are decision variables for skippers). Since there is no information in our data on either investment or intermediate inputs and without prices for fishing inputs, we rely instead on a rank strategy. Specifically, we use the ranking in the total sample of respectively $\ln F H_{i j t}, \ln F A D_{i j t}$ and $\ln F S_{i j t}$ as instruments. The idea is that the rank in the distribution will be highly correlated with its current value for a given input, but the skipper has no information on the ranks of the vessel's fishing inputs at the time of the fishing decision. Indeed, the rank is calculated over all skippers, so that it depends on the choices (current, but also past and future) made by the other captains. As a consequence, the ranks should not be correlated to the unobserved heterogeneity terms (or to a much lower extent if they are).

\footnotetext{
${ }^{31}$ Nevertheless, structural assumptions are needed in both cases. Investment or intermediate inputs have for instance to be strictly monotonic in the unobserved productivity term. When firms operate in competitive input markets, another strategy is an instrumental variable estimation technique with input prices as instrumental variables.
} 
Then, we estimate the three fishing inputs as a function of their rankings, skipper experience, years' fixed effects, and vessel and skipper fixed effects. For these three auxiliary equations, we calculate the predicted residuals, and these residuals are then introduced as additional covariates in (3). According to our results, we find a lower coefficient for fishing hours in the IV specification, with an elasticity of 0.23 against 0.37 under exogeneity. The difference is significant at the 1 percent level, with a statistic equal to 6.65 for the corresponding test. Conversely, inclusion of the rank residuals has little effect on the role played by sets on floating objects and sets on free-swimming schools, since the corresponding residuals are not significant. Overall, a Wald test allows us to reject the assumption of endogeneity of these three fishing inputs, with a test statistic equal to 2.04 .

Another potential shortcoming is the possibility of selective attrition since our data are an unbalanced panel: some skippers enter and leave the sample during all the periods. It should be noted that selection may occur for both efficient and inefficient skippers on a priori grounds. For instance, fishing companies will certainly not be interested in renewing the contract of skippers who have performed poorly over the past season(s). At the same time, there may be some selective attrition for very efficient skippers if they are hired by other foreign companies that are not present in our data or if these skippers decide to change their fishing company to obtain higher revenues. We thus decide to investigate the role of attrition in our data.

We construct a dummy variable $A_{i t}$ such that $A_{i t}=1$ when the skipper leaves the sample at date $t+1$ (after having completed the fishing season $t$ ) and $A_{i t}=0$ otherwise ${ }^{32}$. We estimate the probability $\operatorname{Pr}\left(A_{i t}=1\right)$ using random effect Probit models and present our estimates in Table 4 . In column (1), we introduce our two indicators of skipper experience. We find no influence of either job tenure or overall experience on the probability to leave the sample. In column (2), we add two characteristics related to the vessel, i.e. number of years of use and capacity size. We find that attrition becomes more likely as vessels become older. An explanation is that these vessels have a higher probability to leave the fleet, which generates some mobility and attrition among skippers.

Next, we introduce the lagged value of the log tuna catches as an additional covariate. As shown in column (3), we find a negative coefficient for the lagged volume of catches (significant at 7.8\%). This result suggests that the most productive skippers are more likely to pursue their fishing carrier in the Indian Ocean. Nevertheless, it could be argued that the lagged amount of catches is endogenous as it is the result of the decisions on inputs made by the skipper. To take this concern into account, we turn to an instrumental variable Probit estimation. By definition of the production function, we use the lagged values of the fishing inputs as instruments. As shown in column (4), our main conclusion is that the coefficient associated with lagged catches is no longer significant.

\footnotetext{
${ }^{32}$ We choose to exclude from our sample all the observations present in the last year of our sample (by definition, they all leave the sample in the next period).
} 
On the basis of this specification, we conclude that attrition does not depend on the previous skipper performance and more generally is not affected by the characteristics of the captain ${ }^{33}$. More generally, we believe that attrition has very little influence in our empirical analysis. Indeed, the pseudo $\mathrm{R}^{2}$ associated to column (3) obtained with a standard Probit model is equal to 0.019 . This very low figure may be interpreted as the proportion of attrition that is non-random in our data.

\subsection{The correlation between skipper and vessel fixed effects}

As a final step, we study the correlation between the skipper and vessel heterogeneity terms. The vessel-skipper combinations of fixed effects are shown in Figure 4. According to the data, the correlation between the unobserved skipper and unobserved vessel components is negative (equal to -0.369 ) and significant at the 1 percent level. This means that lower performing skippers tend to catch tuna on more efficient vessels on average. At first glance, this may be a surprising result, but it also highlights the importance and unique insights offered by specifying separate management and firm fixed effects. Instead of our seemingly counter-intuitive result, it could easily be argued that the presence of good managers is more likely to be observed on more efficient vessels. Without both management and firm fixed effects, what looks like the effect of good management could actually be the effect of a more efficient vessel.

A number of explanations come to mind to explain this negative matching. Skippers operating on lower performing vessels may require more motivation than average skippers to realize substantial earnings since income depends on catch levels. Conversely, tuna may be easier to catch on newer vessels due to scale economies and embodiment effects, requiring skippers to exert less effort to increase their catches. Alternatively, owners may assign less efficient skippers to more efficient vessels (and vice versa) to even out and smooth over time skipper-vessel combined performance as measured by catch and revenues. The share index value on which skipper and crew income is based decreases with the vessel size $(0.90 \%$ for a 61 meter long purse seiner, $0.77 \%$ for a $82-$-meter vessel) ${ }^{34}$. By doing so, the company managers want that the skipper and crew income (which depends on the value of catches) is evened out across vessels and helps maintain crew morale and crew retention. The incentive for a skipper might be stronger with this higher share index. Some of the skippers become reluctant to leave a small but familiar boat for a bigger, brand new one joining the fleet and whose effectiveness is uncertain.

Also, more effective skippers may be more skilled at motivating the crew on less effective vessels and reducing any free riding by crew on others. Assigning the most effective skippers to the

\footnotetext{
${ }^{33}$ We perform a Wald test to test whether the skipper's characteristics affect attrition. The resulting $\mathrm{Chi}^{2}$ statistic is equal to 1.34 , with a $p$-value equal to 0.720 .

${ }^{34}$ Skippers are usually granted three shares of the catch value.
} 
least effective vessels might also transfer and improve best practices among the lower performing vessels ${ }^{35}$. These assignments may also more rapidly disseminate process innovations, such as fishing on FADs, by strongly compressing learning effects, as the best skippers teach the crew of less effective vessels and crew of the best-performing vessels teach lower performing skippers. However, skippers are often followed by their own crew when moving from one boat to another one, suggesting that learning-by-doing dissemination must be very limited.

Nevertheless, we believe that our results on matching have to be interpreted with caution for several reasons ${ }^{36}$. First, the correlation between the two sets of fixed effects could be artificially negative because of standard estimation error. We further investigate this issue in an appendix following the methodology described in Andrews et al. (2008). Our main result is that the bias is of small magnitude, meaning that the negative correlation remains. Secondly, the vessel fixed effect does not include technological progress. When a vessel is active for a long time, its equipment is expected to improve over time, compensating for the capital depreciation, and this would make the vessel progressively more efficient for fishing (net of the skipper ability). Our analysis of the match between skippers and vessels is clearly affected by the fact that our measure of the vessel performance is time-invariant.

Thirdly, there is potentially an informational problem. If companies intend to hire successful skippers, they need to observe their performance in fishing. The same argument applies for skippers, for whom information on the level of equipment of vessels is needed before any mobility. However, in our sample, about one-half of the distinct skipper-vessel combinations $(47.6 \%)$ correspond to a first match. By definition, nothing is known on the vessel performance before its first fishing season (and similarly for the skipper). An explanation could thus be that the most efficient skippers prefer to stay on boats whose fishing reputation is well established rather than moving on a new boat.

We then decide to examine the correlation between the vessel and skipper fixed effects as a function of the ranking of the match from the skipper perspective ${ }^{37}$. Our main result is that this rank does not affect the correlation between the two sets of fixed effects. We find a coefficient of correlation equal to -0.370 for the first vessel $(N=146),-0.404$ for the second vessel $(N=82)$ and -0.418 for the third vessel $(\mathrm{N}=39)$. Consequently, the negative relationship between the vessel and skipper fixed effects is not specifically due to a problem of first match since we do not observe

\footnotetext{
${ }^{35}$ Bloom and van Reenen (2007, pp. 1356-1357) observe that on the static side, an industry will not adopt best managerial practices because upgrading management is a costly investment with benefits that do not necessarily outweigh the costs of investment. Hence, although improving management practices increase productivity, profits do not rise. The observed allocation of French skippers to lower performing vessels suggests that these costs are not prohibitive in the French tuna fleet and that profits rise more than they otherwise would as a result.

${ }^{36}$ We leave aside the fact that very recent research has cast doubt on the possibility to identify the positiveness or negativeness of assortative matching (Eeckhout and Kircher, 2011).

${ }^{37}$ Consider for instance a skipper who has caught tuna on three different vessels in our data. The rank of the match is 1 for the first vessel, 2 for the second vessel, and 3 for the last one.
} 
that skippers choose more effective vessels when they move to another boat.

\section{Conclusion}

Within a panel data framework, management and firm fixed effects are traditionally conflated. Exploiting variability in the managerial dimension, this paper is to the best of our knowledge the first one to separately identify the management from firm and time effects in a production technology using a three-way error components model and a unique panel data set tracking multiple managers for each firm in each year for an industry over 27 years.

We find that fishing hours and number of sets, respectively on floating objects and on freeswimming schools, explain more than $70 \%$ of variation in tuna catches over the period. A rise of 1 percent in fishing time increases the total catches by 0.374 percent. The contribution of year, vessel and skipper fixed effects are respectively equal to $2.7 \%, 5.1 \%$ and $5.7 \%$. Bigger vessels seem more likely than smaller ones to use FADs, or simply allow for more time fishing (power, speed). A distinction between movers (those skippers changing vessels in the course of time) and non-movers indicate that the latter rely significantly less on their vessel's input levels (number of FAD buoys and fishing time) or on their boat, and more on their personal skills and environmental conditions as compared to movers.

Also, our results show that the firm's management is fixed in the sense that inter-vessel differences due to skippers remains fixed. Skipper learning-by-doing, as measured by experience and job tenure and which captures time-varying management, plays no significant role in this industry. Neither overall experience nor experience with a particular vessel affects a skipper's success. Skipper skill may simply be "innate" as some in the industry suggest: either a skipper "has it" or not. Finally, separating the management and firm effects gives the unexpected result of negative matching in which less performing skippers (managers) tend to catch tuna on more efficient vessels (firms) on average. A possible explanation would be the way for corporate managers to even out crew income across vessels and to help crew retention and maintain morale.

A lesson of our paper for other studies of firm production adopting a fixed effect framework to management is the importance of distinguishing between the management and firm effects. Assessing their respective contribution using variance decomposition is a subject of interest as the role played by managers and firms will certainly depend on the type of production. A difficulty that has to be kept in mind when estimating such three-way error component models is the need of high quality data. Although our data on the Indian Ocean Tuna Fishery are unique in terms of quality and length of period, the limited sample size leads to an identification of the vessel and skipper fixed effects that is based on a small number of moves in some cases. 
A shortcoming of our data is undoubtedly the lack of detailed characteristics of both managers and firms. Such information is necessary to delve deeper into what constitutes effective management and effective firms. In our setting, some information on how skippers succeed in managing their crew, on their ability in using advanced electronic devices or on their risk attitudes for instance would have been useful to better understand the role played by the skipper in tuna catches and in delving deeper into learning-by-doing and -using. Data on code groups would inform on relationship learning. More detailed data on the composition of the crew members, in terms of fishing experience in particular, could also help to explain the (complex) relationship on board that is expected to strongly impact productivity.

A final comment concerns the policy implications of our results for the public regulation of industries exploiting common resources, or at least the Indian Ocean tuna purse seine fishery. The matching between the more efficient skippers and less efficient vessels facilitates in a way the management of fishing capacity through effort controls, since the combination of good skippers operating on less effective boats may well result in a rather neutral effect on the variability of catches. Of far greater importance appears to be the role of FADs and fishing time in catch levels. The effectiveness of sets on floating objects was estimated as twice that of free school sets. This technique being more subject to investment choices and vessel sizes rather than skipper decisions, the number of authorized FADs per vessel becomes a key control variable for managers. Moreover, if catch limitation is the goal, regulators could effectively reduce the number of fishing hours by capping the number of days at sea per vessel, as achieved successfully by the Vessel Monitoring System (VMS) implemented in the West and Central Pacific tuna fisheries. 


\section{References}

Abowd, J.M., Kramarz, F., Margolis, D.N. 1999. "High wage workers and high wage firms", Econometrica, vol. 67, pp. 251-333.

Andrews, M., Gill, L., Schank, T., Upward, R. 2008. "High wage workers and low wage firms: negative assortative matching or limited mobility bias?", Journal of the Royal Statistical Society Series A, vol. 171, pp. 673-697.

Andrews, M., Schank T., Upward, R. 2006. "Practical fixed-effects estimation methods for the threeway error-components model", Stata Journal, vol. 6, pp. 461-481.

Argote, L., Beckman, S.L. , Epple D. 1990. "The persistence and transfer of learning in industrial settings", Management Science, vol. 36, pp. 140-154.

Black, S., Lynch L. 2001. "How to compete: The impact of workplace practices and information technology on productivity", Review of Economics and Statistics, vol. 83, pp. 434-445.

Bloom, N., van Reenen, J. 2007. "Measuring and explaining management practices across firms and countries", Quarterly Journal of Economics, vol. 72, pp. 1350-1408.

Campbell, H.F., Nicholl, R.B., 1994. "Can purse-seiners target yellowfin tuna?", Land Economics, vol. 70, pp. 345-353.

Eeckhout, J., Kircher, P. 2011. "Identifying sorting - In theory", Review of Economic Studies, vol. 78, pp. 872-906.

Griliches, Z., Mairesse, J. 1998. "Production functions: The search for identification”, in Strøm S., ed., Econometrics and Economic Theory in the Twentieth Century: The Ragnar Frisch Centennial Symposium, Cambridge University Press, Cambridge.

Guillotreau, P., Salladarre, F., Dewals, P., Dagorn, L. 2011, “Fishing tuna around Fish Aggregating Devices (FADs) vs free swimming schools: Skipper decision and other determining factors", Fisheries Research, vol. 109, pp. 234-242.

Heady, E.O. 1946. "Production functions from a random sample of farms", Journal of Farm Economics, vol. 28, pp. 989-1004.

Hoch, I. 1955. "Estimation of production function parameters and testing for efficiency", Econometrica, vol. 23, pp. 325-326.

Hoch, I. 1962. "Estimation of production function parameters combining time-series and crosssection data", Econometrica, vol. 30, pp. 34-53.

Holtz-Eakin, D., Joulfaian, D., Rosen, H. 1993. "The Carnegie Conjecture: Some empirical evidence", Quarterly Journal of Economics, vol. 108, pp. 413-436.

Horrace, W., Schnier, K. 2010. "Fixed-effect estimation of highly-mobile production technologies", American Journal of Agricultural Economics, vol. 92, pp. 1432-1445.

Hulten, C. 1992. "Growth accounting when technical change is embodied in capital", American Economic Review, vol. 82, pp. 964-980.

Kellogg, R. 2011. "Learning by drilling: Interfirm learning and relationship persistence in the Texas oil patch," Quarterly Journal of Economics, vol. 126, pp. 1961-2004.

Kirkley J., Squires, D., Strand, I.E. 1998. "Characterizing managerial skill and technical efficiency in a fishery", Journal of Productivity Analysis, vol. 9, pp. 145-160.

Levinsohn, J., Petrin, A. 2003. "Estimating production functions using inputs to control for unobservables", Review of Economic Studies, vol. 70, pp. 317-341.

Marsac, F., Le Blanc, J.L. 1999. “Oceanographic changes during the 1997-1998 El Niño in the Indian Ocean and their impact on fisheries", IOTC Proceedings, $\mathrm{n}^{\circ} 2$, pp. 147-157.

Massell, B.F. 1967. "Elimination of management bias from production functions fitted to crosssection data: A model and an application to African agriculture", Econometrica, vol. 35, pp. 495-508. 
Medford, R. 1986. "Introducing management into production functions", Review of Economics and Statistics, vol. 68, pp. 96-104.

Ménard, F., Marsac, F., Bellier, E., Cazelles, B. 2007. "Climatic oscillations and tuna catch rates in the Indian Ocean: A wavelet approach to time series analysis", Fisheries Oceanography, vol. 16, pp. 95-104.

Meyers, G., Mc Intosh, P., Pigot, L., Pook, M. 2007. "The years of El Niño, La Niña, and interactions with the Tropical Indian Ocean", Journal of Climate, vol. 20, pp. 2872-2880.

Miyake, M.P., Guillotreau, P., Sun, C.-H., Ishimura, G. 2010. "Recent developments in tuna industry: Stocks, fisheries, management, processing, trade and markets", mimeo, FAO Technical Report 543.

Mundlak, Y. 1961. "Empirical production function free of management bias", Journal of Farm Economics, vol. 43, pp. 44-56.

Mundlak, Y. 1978. "On the pooling of time series and cross section data", Econometrica, vol. 46, pp. 69-85.

Mundlak, Y. 2001. "Production and supply", in B. Gardner, G. Rausser, eds., Handbook of Agricultural Economics, vol. 1, Elsevier, North-Holland.

Mundlak, Y., Hoch, I. 1965. "Consequences of alternative specifications in estimation of CobbDouglas production functions", Econometrica, vol. 33, pp. 814-828.

Nickell, S. 1996. "Competition and corporate performance", Journal of Political Economy, vol. 104, pp. 724-746.

Olley, G.S., Pakes, A. 1996. "The dynamics of productivity in the telecommunications equipment industry", Econometrica, vol. 64, pp. 1263-1298.

Pascoe, S., Coglan L., 2002. "The contribution of unmeasurable inputs to fisheries production: An analysis of technical efficiency of fishing vessels in the English Channel", American Journal of Agricultural Economics, vol. 84, pp. 585-597.

Potier, M., Ménard, F., Cherel, Y., Lorrain, A., Sabatié, R., Marsac F. 2007. "Role of pelagic crustaceans in the diet of the long-nose lancetfish Alepisaurus ferox in the Seychelles waters", African Journal of Marine Science, vol. 29, pp. 113-122.

Schmidt, K. 1997. "Managerial incentives and product market competition", Review of Economic Studies, vol. 64, pp. 191-213.

Schmidt, P., Sickles, R. 1984. "Production frontiers with panel data", Journal of Business and Economic Statistics, vol. 2, pp. 367-374.

Squires, D. 1992. "Productivity growth in common property resource industries: An application to the Pacific Coastal trawl industry", Rand Journal of Economics, vol. 23, pp. 221-236.

Squires, D., Kirkley, J., 1999. "Skipper skill and panel data in fishing industries", Canadian Journal of Fisheries and Aquatic Sciences, vol. 56, pp. 2011-2018.

Syverson, C. 2004. "Market structure and productivity: A concrete example", Journal of Political Economy, vol. 112, pp. 1181-1222.

Tintner, G., Brownlee O.H. 1944. "Production functions derived from farm records", Journal of Farm Economics, vol. 26, pp. 566-571.

Viswanathan, K., Ishak, O., Jeon, Y., Kirkley, J., Squires D., Susilowati I. 2001. "Fishing skill in developing countries: The Kedah, Malaysia trawl fishery", Marine Resource Economics, vol. 16 , pp. 293-314. 


\section{Appendix. Bias and correlation between vessel and skipper fixed effects}

In the context of labor markets, a few studies have recently focused on the relationship between the unobserved worker and firm components of wages and they have almost all found a negative correlation (see the references in Andrews et al., 2008). While an interpretation is that negative assortative matching is the rule on labor markets, Andrews et al. (2008) have argued that the negative correlation between the two sets of fixed effects (respectively worker and firm) could be affected by standard estimation error. They show that the estimated correlation between the fixed effects is biased downwards in such multiple error component models.

The intuition behind that result stems from the definition of the skipper fixed effect. For each skipper, the unobserved heterogeneity term is given by:

$$
\hat{\delta}_{i}=\overline{\ln Q_{l}}-\sum_{k} \hat{\alpha}_{k} \overline{\ln X_{k, l}}-\overline{\hat{\theta}}_{J}
$$

As shown in (A1), each estimated vessel fixed effect $\hat{\theta}_{j}$ is part of several skipper fixed effects $\hat{\delta}_{i}$. Since the $\hat{\theta}_{j}$ are subject to sampling variation, then an over-estimation (or under-estimation) of $\hat{\theta}_{j}$ will imply an under-estimation (respectively over-estimation) of the $\hat{\delta}_{i}$. Andrews et al. (2008) derive the following formula for the sample covariance $S_{\widehat{\theta} \widehat{\delta}}$ between the two unobserved components:

$$
\operatorname{bias}\left[S_{\widehat{\theta} \widehat{\delta}}\right]=-\frac{\sigma_{\varepsilon}^{2}}{N^{*}-1} \operatorname{tr}\left\{F^{\prime} M_{Z} D\left(D^{\prime} M_{Z} D\right)^{-1} D^{\prime} A F\left(F^{\prime} M_{V} F\right)^{-1}\right\}
$$

with $\sigma_{\varepsilon}^{2}$ the variance of the error term $\varepsilon, N^{*}$ the total number of observations, $F$ and $D$ two matrix of respectively vessel and skipper dummies and $V=[Z, D]$ a matrix combining inputs and skipper dummies, $M_{Z}=I-Z\left(Z^{\prime} Z\right)^{-1} Z^{\prime}, M_{V}=I-V\left(V^{\prime} V\right)^{-1} V^{\prime}$ and $A=I-1\left(1^{\prime} 1\right)^{-1} 1^{\prime}$ with 1 a column vector of 1 . The bias thus depends on several factors, including sample size, intensity of mobility of skippers among the vessels as well as the error variance of the model.

Since our estimated correlation between $\hat{\theta}_{j}$ and $\hat{\delta}_{i}$ is equal to -0.369 , a large downward bias in the covariance is needed to get an unbiased positive correlation between the two sets of fixed effects. Unfortunately, we do not find such result when applying (A2) to our data. Matrix calculations lead to a value of around -0.05 for the bias, which remains small compared to the coefficient of correlation. Our data then allow us to reject the assumption of positive assortative matching between skippers and vessels in the Indian Ocean tuna fishery under consideration. 
Figure 1. Number of skippers per vessel

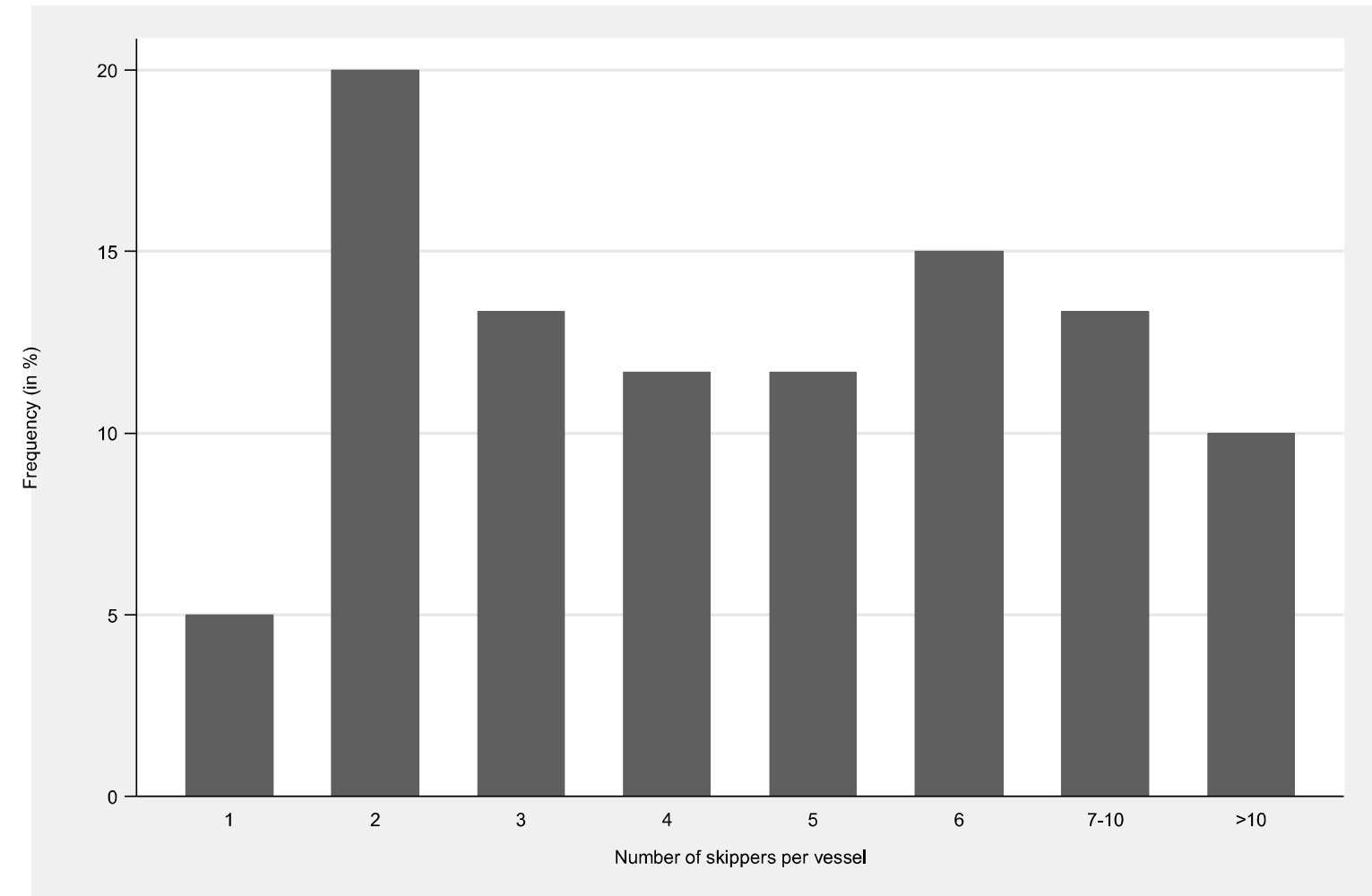

Source: data from Observatoire Thonier, IRD, authors' calculations.

Figure 2. Catch of tuna and average proportion of FAD sets, by year

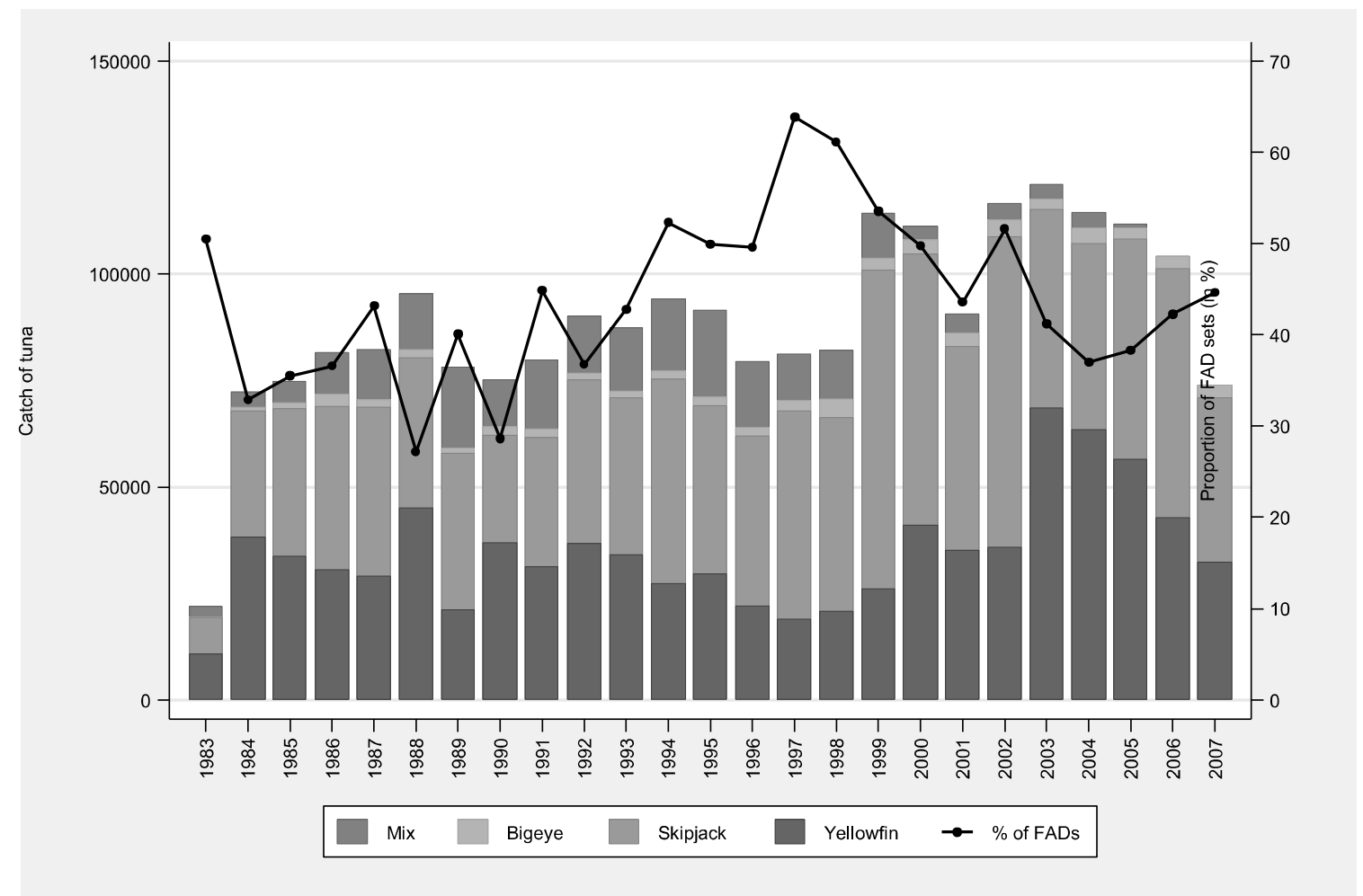

Source: data from Observatoire Thonier, IRD, authors' calculations. 
Figure 3. Time fixed effects

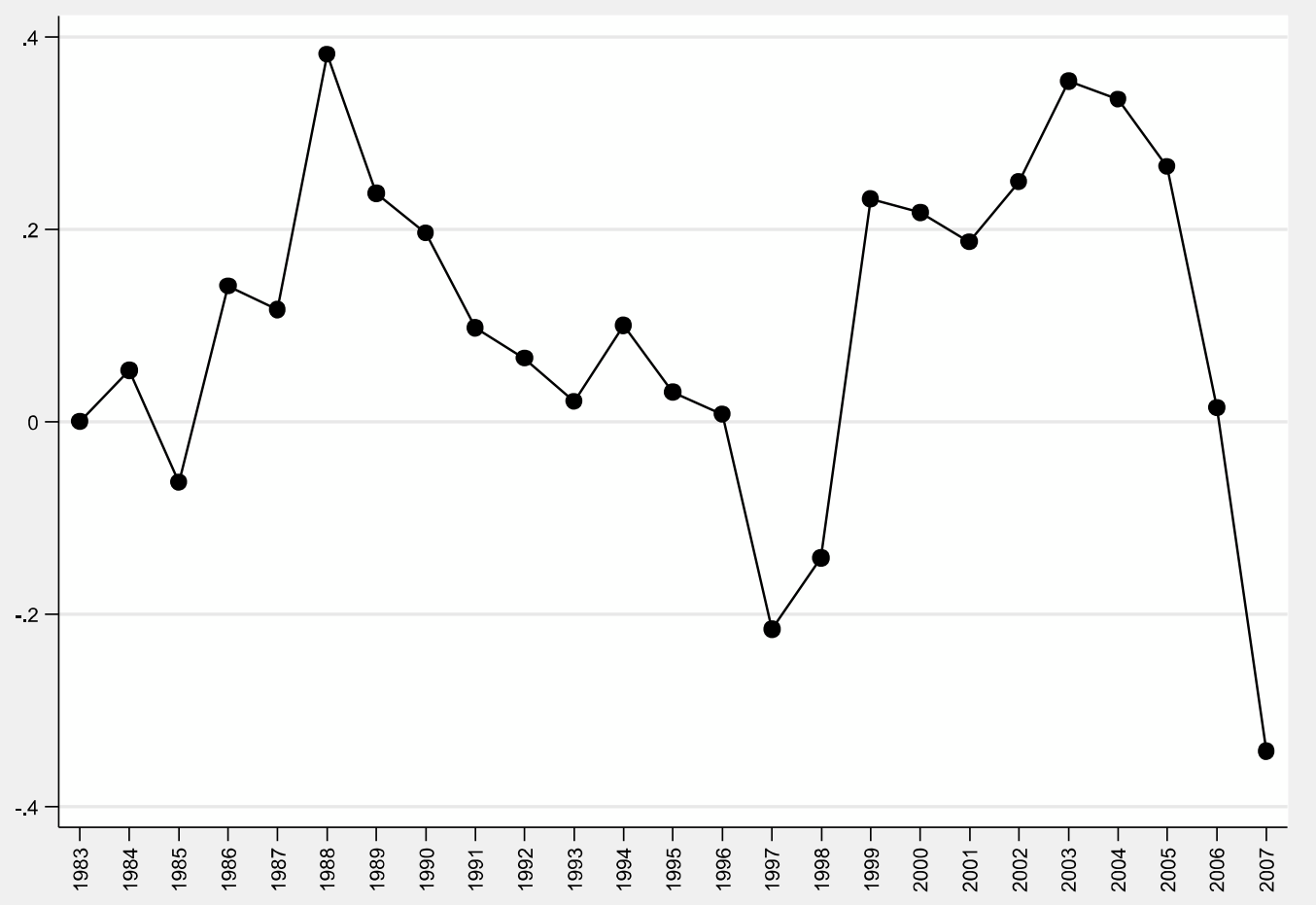

Source: data from Observatoire Thonier, IRD, authors' calculations.

Figure 4. Correlation between vessel and skipper fixed effects

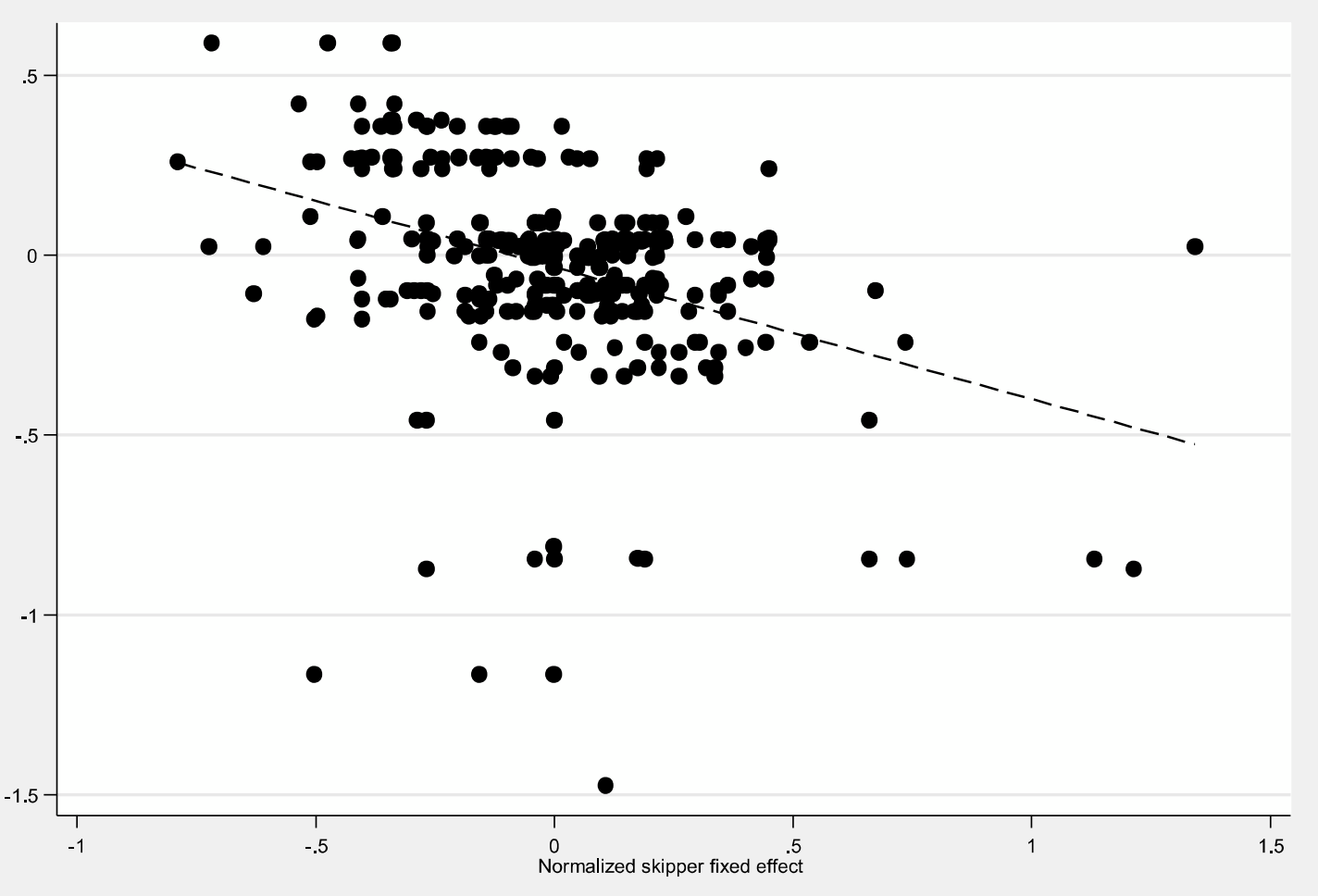

Source: data from Observatoire Thonier, IRD, authors' calculations. 
Table 1. Descriptive statistics of the sample

\begin{tabular}{lcccc}
\hline Variables & All & $\begin{array}{c}\text { Non-moving } \\
\text { skippers }\end{array}$ & Moving skippers & $\begin{array}{c}\text { Dif: Movers - } \\
\text { non-movers }\end{array}$ \\
\hline Catch of tuna $(\mathrm{In})$ & 7.139 & 7.023 & 7.176 & $0.153^{* *}$ \\
& $(1.073)$ & $(0.911)$ & $(1.116)$ & $(0.073)$ \\
Fishing hours $(\mathrm{In})$ & 7.007 & 6.971 & 7.018 & 0.047 \\
& $(0.710)$ & $(0.655)$ & $(0.726)$ & $(0.048)$ \\
Sets on floating objects $(\mathrm{In})$ & 3.253 & 3.105 & 3.299 & $0.194^{* *}$ \\
& $(1.103)$ & $(1.103)$ & $(1.099)$ & $(0.075)$ \\
Sets on free-swimming schools $(\mathrm{In})$ & 3.480 & 3.461 & 3.486 & 0.025 \\
& $(1.140)$ & $(1.104)$ & $(1.152)$ & $(0.078)$ \\
Skipper experience $(\mathrm{In})$ & 1.543 & 1.045 & 1.698 & $0.653^{* * *}$ \\
& $(0.881)$ & $(0.850)$ & $(0.832)$ & $(0.057)$ \\
Skipper vessel-specific experience $(\mathrm{In})$ & 1.006 & 1.045 & 0.994 & -0.051 \\
& $(0.782)$ & $(0.850)$ & $(0.760)$ & $(0.053)$ \\
\hline Number of observations & 1197 & 284 & 913 & \\
\hline
\end{tabular}

Source: data from Observatoire Thonier, IRD, authors' calculations.

Note: standard errors are in parentheses. Significance levels are $1 \%\left({ }^{* * *}\right), 5 \%\left({ }^{* *}\right)$ and $10 \%\left({ }^{*}\right)$. Skipper experience is the total number of fishing seasons in the Indian Ocean. Skipper-vessel specific experience is the number of seasons that a skipper has spent on a given vessel. 
Table 2. Three-way fixed effects estimates of log tuna catches

\begin{tabular}{|c|c|c|c|}
\hline Variables & $\begin{array}{l}\text { (1) } \\
\text { All }\end{array}$ & $\begin{array}{c}\text { (2) } \\
\text { Movers }\end{array}$ & $\begin{array}{c}(3) \\
\text { Non-movers }\end{array}$ \\
\hline Fishing hours (In) & $\begin{array}{c}0.374^{* * *} \\
(5.26)\end{array}$ & $\begin{array}{c}0.381 * * * \\
(4.57)\end{array}$ & $\begin{array}{c}0.392^{* * *} \\
(3.77)\end{array}$ \\
\hline Sets on floating objects (In) & $\begin{array}{c}0.453^{* * *} \\
(11.63)\end{array}$ & $\begin{array}{c}0.486 * * * \\
(10.65)\end{array}$ & $\begin{array}{c}0.266^{* * *} \\
(4.67)\end{array}$ \\
\hline Sets on free-swimming schools (In) & $\begin{array}{c}0.230 * * * \\
(8.02)\end{array}$ & $\begin{array}{l}0.211^{* * *} \\
(6.48)\end{array}$ & $\begin{array}{l}0.286 * * * \\
(6.39)\end{array}$ \\
\hline Skipper overall experience (In) & $\begin{array}{l}0.020 \\
(0.41)\end{array}$ & $\begin{array}{l}0.003 \\
(0.06)\end{array}$ & $\begin{array}{l}-0.067 \\
(-0.59)\end{array}$ \\
\hline Skipper vessel-specific experience (In) & $\begin{array}{l}-0.012 \\
(-0.47)\end{array}$ & $\begin{array}{l}-0.020 \\
(-0.73)\end{array}$ & \\
\hline $\begin{array}{l}\text { Year fixed effects } \\
\text { HO: } \ln (\text { FADS })=\ln \text { (free schools) }\end{array}$ & YES & YES & YES \\
\hline F-stat; prob. & $35.27 ; 0.000$ & $38.81 ; 0.000$ & $0.11 ; 0.734$ \\
\hline Number of observations & 1197 & 913 & 284 \\
\hline Number of vessels & 60 & 52 & 7 \\
\hline Number of skippers & 159 & 82 & 11 \\
\hline $\mathrm{R}^{2}$ & 0.903 & 0.902 & 0.935 \\
\hline
\end{tabular}

Source: data from Observatoire Thonier, IRD, authors' calculations.

Note: robust standard errors are in parentheses. Significance levels are respectively $1 \%\left({ }^{* * *}\right), 5 \%\left({ }^{* *}\right)$ and $10 \%\left({ }^{*}\right)$. 
Table 3. Variance decomposition of the fixed effect models

\begin{tabular}{|c|c|c|c|c|c|c|}
\hline \multirow[t]{2}{*}{ Decomposition } & \multicolumn{2}{|c|}{$\begin{array}{l}(1) \\
\text { All }\end{array}$} & \multicolumn{2}{|c|}{$\begin{array}{c}(2) \\
\text { Movers } \\
\end{array}$} & \multicolumn{2}{|c|}{$\begin{array}{c}\text { (3) } \\
\text { Non-movers }\end{array}$} \\
\hline & value & $\%$ & value & & value & \\
\hline Var(inputs) & 0.832 & 72.3 & 0.891 & 71.5 & 0.500 & 60.3 \\
\hline Var(year fixed effects) & 0.031 & 2.7 & 0.040 & 3.2 & 0.046 & 5.6 \\
\hline Var(vessel fixed effects) & 0.059 & 5.1 & 0.057 & 4.6 & 0.079 & 9.5 \\
\hline Var(skipper fixed effects) & 0.065 & 5.7 & 0.046 & 3.7 & & \\
\hline 2*cov(inputs, year fixed effects) & 0.017 & 1.4 & 0.014 & 1.1 & 0.074 & 9.0 \\
\hline $2 * \operatorname{cov}($ inputs, vessel fixed effects) & 0.108 & 9.4 & 0.107 & 8.6 & 0.078 & 9.4 \\
\hline $2^{*} \operatorname{cov}($ inputs, skipper fixed effects) & -0.014 & -1.2 & 0.014 & 1.1 & & \\
\hline 2*cov(year fixed effects, vessel fixed effects) & 0.000 & 0.0 & -0.002 & -0.1 & -0.001 & -0.2 \\
\hline $2 * \operatorname{cov}($ year fixed effects, skipper fixed effects) & -0.003 & -0.3 & -0.002 & -0.2 & & \\
\hline $2 * \operatorname{cov}($ vessel fixed effects, skipper fixed effects) & -0.057 & -5.0 & -0.040 & -3.2 & & \\
\hline Var(residual) & 0.112 & 9.7 & 0.123 & 9.8 & 0.054 & 6.5 \\
\hline Variance(log tuna catches) & 1.150 & 100.0 & 1.246 & 100.0 & 0.830 & 100.0 \\
\hline
\end{tabular}

Source: data from Observatoire Thonier, IRD, authors' calculations.

Note: the variance decomposition is based on estimates reported in Table 2. For non-movers, we cannot disentangle the vessel and skipper fixed effects. We refer to vessel fixed effects in the presentation, but this includes both the vessel and skipper unobserved heterogeneity. 
Table 4. Random effect Probit estimates of attrition

\begin{tabular}{|c|c|c|c|c|}
\hline Variables & $\begin{array}{c}\text { (1) } \\
\text { RE Probit }\end{array}$ & $\begin{array}{c}\text { (2) } \\
\text { RE Probit }\end{array}$ & $\begin{array}{c}(3) \\
\text { RE Probit }\end{array}$ & $\begin{array}{c}\text { (4) } \\
\text { IV Probit }\end{array}$ \\
\hline Constant & & & & \\
\hline Skipper experience (In) & $\begin{array}{l}-0.026 \\
(-0.36)\end{array}$ & $\begin{array}{l}-0.027 \\
(-0.37)\end{array}$ & $\begin{array}{l}-0.018 \\
(-0.20)\end{array}$ & $\begin{array}{l}-0.035 \\
(-0.36)\end{array}$ \\
\hline Skipper vessel-specific experience (In) & $\begin{array}{l}-0.008 \\
(-0.10)\end{array}$ & $\begin{array}{l}-0.034 \\
(-0.42)\end{array}$ & $\begin{array}{l}0.023 \\
(0.26)\end{array}$ & $\begin{array}{l}-0.002 \\
(-0.03)\end{array}$ \\
\hline Number of years of vessel use & & $\begin{array}{c}0.025 * * * \\
(2.84)\end{array}$ & $\begin{array}{c}0.025 * * * \\
(2.61)\end{array}$ & $\begin{array}{c}0.026 * * * \\
(2.65)\end{array}$ \\
\hline Capacity size of the vessel /100 & & $\begin{array}{l}-0.013 \\
(-0.89)\end{array}$ & $\begin{array}{l}-0.011 \\
(-0.69)\end{array}$ & $\begin{array}{l}-0.012 \\
(-0.76)\end{array}$ \\
\hline Lagged volume of catches (exogenous) & & & $\begin{array}{c}-0.101^{*} \\
(-1.76)\end{array}$ & \\
\hline Lagged volume of catches (endogenous) & & & & $\begin{array}{l}-0.049 \\
(-0.71) \\
\end{array}$ \\
\hline Number of observations & 1145 & 1145 & 981 & 981 \\
\hline Number of skippers & 156 & 156 & 138 & 138 \\
\hline Log likelihood & -386.1 & -381.3 & -323.2 & -879.0 \\
\hline
\end{tabular}


APPENDIX NOT FOR PUBLICATION - ROBUSTNESS CHECKS

Table A. Three-way fixed effects estimates of log tuna catches, by species

\begin{tabular}{|c|c|c|c|c|}
\hline Variables & $\begin{array}{c}\text { (1) } \\
\text { Yellowfin } \\
\end{array}$ & $\begin{array}{c}\text { (2) } \\
\text { Skipjack }\end{array}$ & $\begin{array}{c}\text { (3) } \\
\text { Bigeye } \\
\end{array}$ & $\begin{array}{l}(4) \\
\text { Mix } \\
\end{array}$ \\
\hline Fishing hours (In) & $\begin{array}{l}0.392^{*} \\
(1.83)\end{array}$ & $\begin{array}{l}0.435 \\
(1.49)\end{array}$ & $\begin{array}{c}1.324^{* * *} \\
(3.46)\end{array}$ & $\begin{array}{l}0.168 \\
(0.36)\end{array}$ \\
\hline Sets on floating objects (In) & $\begin{array}{l}0.133 \\
(1.40)\end{array}$ & $\begin{array}{l}0.984^{* * *} \\
(6.78)\end{array}$ & $\begin{array}{c}0.630 * * * \\
(3.30)\end{array}$ & $\begin{array}{c}0.660 * * * \\
(2.67)\end{array}$ \\
\hline Sets on free-swimming schools (In) & $\begin{array}{l}0.909 * * * \\
(7.48)\end{array}$ & $\begin{array}{l}0.058 \\
(0.57)\end{array}$ & $\begin{array}{l}-0.009 \\
(-0.05)\end{array}$ & $\begin{array}{l}0.055 \\
(0.25)\end{array}$ \\
\hline Skipper overall experience (In) & $\begin{array}{l}-0.159 \\
(-0.81)\end{array}$ & $\begin{array}{l}-0.231 \\
(-1.56)\end{array}$ & $\begin{array}{c}-1.105^{* * *} \\
(-3.05)\end{array}$ & $\begin{array}{l}0.383 \\
(0.84)\end{array}$ \\
\hline Skipper vessel-specific experience (In) & $\begin{array}{l}0.130 \\
(0.87)\end{array}$ & $\begin{array}{c}-0.179 * * \\
(-2.15)\end{array}$ & $\begin{array}{c}0.502 * * \\
(2.35)\end{array}$ & $\begin{array}{l}0.093 \\
(0.39)\end{array}$ \\
\hline $\begin{array}{l}\text { Year fixed effects } \\
\text { HO: } \ln (F A D S)=\ln (\text { free schools) }\end{array}$ & YES & YES & YES & YES \\
\hline F-stat ; prob. & $44.45 ; 0.000$ & $52.65 ; 0.000$ & $8.18 ; 0.005$ & $4.97 ; 0.027$ \\
\hline Number of observations & 1197 & 1197 & 1197 & 1197 \\
\hline Number of vessels & 60 & 60 & 60 & 60 \\
\hline Number of skippers & 159 & 159 & 159 & 159 \\
\hline $\mathrm{R}^{2}$ & 0.645 & 0.669 & 0.508 & 0.532 \\
\hline
\end{tabular}

Source: data from Observatoire Thonier, IRD, authors' calculations.

Note: robust standard errors are in parentheses. Significance levels are respectively $1 \%\left({ }^{* * *}\right), 5 \%\left({ }^{* *}\right)$ and $10 \%\left({ }^{*}\right)$. 
Table B. Three-way fixed effects estimates of tuna catches, linear and quadratic production functions

\begin{tabular}{|c|c|c|}
\hline Variables & $\begin{array}{c}\text { (1) } \\
\text { Linear specification }\end{array}$ & $\begin{array}{c}\text { (2) } \\
\text { Quadratic } \\
\text { specification }\end{array}$ \\
\hline Fishing hours & $\begin{array}{c}0.272^{* * *} \\
(4.42)\end{array}$ & $\begin{array}{l}0.270 \\
(1.41)\end{array}$ \\
\hline Sets on floating objects & $\begin{array}{c}21.830 * * * \\
(17.66)\end{array}$ & $\begin{array}{l}25.916^{* * *} \\
(7.92)\end{array}$ \\
\hline Sets on free-swimming schools & $\begin{array}{c}11.782^{* * *} \\
(9.69)\end{array}$ & $\begin{array}{c}7.897 * * * \\
(3.09)\end{array}$ \\
\hline Skipper overall experience & $\begin{array}{c}-12.292 \\
(-1.26)\end{array}$ & $\begin{array}{c}-34.383^{*} \\
(-1.86)\end{array}$ \\
\hline Skipper vessel-specific experience & $\begin{array}{l}10.957 \\
(1.11)\end{array}$ & $\begin{array}{l}7.836 \\
(0.33)\end{array}$ \\
\hline Fishing hours * Fishing hours /100 & & $\begin{array}{l}0.001 \\
(0.09)\end{array}$ \\
\hline Fishing hours * Sets on floating objects /10 & & $\begin{array}{l}-0.006 \\
(-0.17)\end{array}$ \\
\hline Fishing hours * Sets on free-swimming schools /10 & & $\begin{array}{l}-0.028 \\
(-1.01)\end{array}$ \\
\hline Fishing hours* Skipper overall experience /10 & & $\begin{array}{c}0.259 * * * \\
(2.68)\end{array}$ \\
\hline Fishing hours * Skipper vessel-specific experience /10 & & $\begin{array}{l}-0.025 \\
(-0.12)\end{array}$ \\
\hline Sets on floating objects * Sets on floating objects & & $\begin{array}{c}-0.095^{* * *} \\
(-3.06)\end{array}$ \\
\hline Sets on floating objects * Sets on free-swimming schools & & $\begin{array}{c}0.098^{* *} \\
(2.19)\end{array}$ \\
\hline Sets on floating objects * Skipper overall experience & & $\begin{array}{l}0.152 \\
(0.85)\end{array}$ \\
\hline Sets on floating objects * Skipper vessel-specific experience & & $\begin{array}{l}-0.267 \\
(-0.83)\end{array}$ \\
\hline Sets on free-swimming schools * Sets on free-swimming schools & & $\begin{array}{l}0.023 \\
(1.05)\end{array}$ \\
\hline Sets on free-swimming schools * Skipper overall experience & & $\begin{array}{l}-0.154 \\
(-0.87)\end{array}$ \\
\hline Sets on free-swimming schools * Skipper vessel-specific experience & & $\begin{array}{l}0.319 \\
(0.92)\end{array}$ \\
\hline Skipper overall experience $*$ Skipper overall experience & & $\begin{array}{l}-0.547 \\
(-0.93)\end{array}$ \\
\hline Skipper overall experience ${ }^{*}$ Skipper vessel-specific experience & & $\begin{array}{l}0.227 \\
(0.09)\end{array}$ \\
\hline Skipper vessel-specific experience * Skipper vessel-specific experience & & $\begin{array}{l}-0.443 \\
(-0.18)\end{array}$ \\
\hline Year fixed effects & YES & YES \\
\hline Number of observations & 1197 & 1197 \\
\hline Number of vessels & 60 & 60 \\
\hline Number of skippers & 159 & 159 \\
\hline$R^{2}$ & 0.909 & 0.883 \\
\hline
\end{tabular}

Source: data from Observatoire Thonier, IRD, authors' calculations.

Note: robust standard errors are in parentheses. Significance levels are respectively $1 \%\left({ }^{* * *}\right), 5 \%\left({ }^{* *}\right)$ and $10 \%\left({ }^{*}\right)$. 
Table C. Three-way fixed effects estimates of log tuna catches, by fixed effect specification

\begin{tabular}{|c|c|c|c|c|}
\hline Variables & $\begin{array}{c}\text { (1) } \\
\text { Vessel } \\
\text { fixed effect }\end{array}$ & $\begin{array}{c}\text { (2) } \\
\text { Skipper } \\
\text { fixed effect }\end{array}$ & $\begin{array}{c}\text { (3) } \\
\text { Vessel-skipper } \\
\text { fixed effect }\end{array}$ & $\begin{array}{c}\text { (4) } \\
\text { Vessel fixed } \\
\text { effect + skipper } \\
\text { fixed effect }\end{array}$ \\
\hline Fishing hours (In) & $\begin{array}{c}0.467 * * * \\
(6.69)\end{array}$ & $\begin{array}{c}0.283^{* * * *} \\
(3.59)\end{array}$ & $\begin{array}{c}0.410 * * * \\
(5.22)\end{array}$ & $\begin{array}{c}0.374 * * * \\
(5.26)\end{array}$ \\
\hline Sets on floating objects (In) & $\begin{array}{c}0.401 * * * \\
(10.95)\end{array}$ & $\begin{array}{c}0.507 * * * \\
(11.57)\end{array}$ & $\begin{array}{c}0.419 * * * \\
(10.35)\end{array}$ & $\begin{array}{c}0.453 * * * \\
(11.63)\end{array}$ \\
\hline Sets on free-swimming schools (In) & $\begin{array}{c}0.221^{* * * *} \\
(8.47)\end{array}$ & $\begin{array}{c}0.283^{* * * *} \\
(8.15)\end{array}$ & $\begin{array}{c}0.227^{* * *} \\
(7.04)\end{array}$ & $\begin{array}{c}0.230 * * * \\
(8.02)\end{array}$ \\
\hline Skipper overall experience (In) & $\begin{array}{l}0.001 \\
(0.04)\end{array}$ & $\begin{array}{l}0.007 \\
(0.16)\end{array}$ & $\begin{array}{c}0.222 * * * \\
\quad(3.24)\end{array}$ & $\begin{array}{l}0.020 \\
(0.41)\end{array}$ \\
\hline Skipper vessel-specific experience $(\ln )$ & $\begin{array}{l}0.014 \\
(0.71)\end{array}$ & $\begin{array}{l}-0.033 \\
(-1.29)\end{array}$ & $\begin{array}{c}-0.172 * * * \\
(-2.73)\end{array}$ & $\begin{array}{l}-0.012 \\
(-0.47)\end{array}$ \\
\hline Year fixed effects & YES & YES & YES & YES \\
\hline HO: $\ln (F A D S)=\ln ($ free schools) & & & & \\
\hline F-stat ; prob. & $18.01 ; 0.000$ & $34.31 ; 0.000$ & $22.80 ; 0.000$ & $35.58 ; 0.000$ \\
\hline Number of observations & 1197 & 1197 & 1197 & 1197 \\
\hline Number of vessels & 60 & & & 60 \\
\hline Number of skippers & & 159 & 320 & 159 \\
\hline $\mathrm{R}^{2}$ & 0.879 & 0.888 & 0.919 & 0.903 \\
\hline
\end{tabular}

Source: data from Observatoire Thonier, IRD, authors' calculations.

Note: robust standard errors are in parentheses. Significance levels are respectively $1 \%\left({ }^{* * *}\right), 5 \%\left({ }^{* *}\right)$ and $10 \%\left({ }^{*}\right)$. 
Table D. Three-way fixed effects estimates of log tuna catches - endogeneity of fishing inputs

\begin{tabular}{|c|c|c|c|c|}
\hline Variables & $\begin{array}{c}\text { (1) } \\
\text { Fishing hours } \\
(\ln )\end{array}$ & $\begin{array}{c}\text { (2) } \\
\text { Sets on floating } \\
\text { objects (In) }\end{array}$ & $\begin{array}{c}\text { (3) } \\
\text { Sets on free- } \\
\text { swimming } \\
\text { schools (In) }\end{array}$ & $\begin{array}{c}\text { (4) } \\
\text { Tuna catches } \\
(\ln )\end{array}$ \\
\hline Fishing hours (In) & & & & $\begin{array}{c}0.202^{* * *} \\
(3.06)\end{array}$ \\
\hline Sets on floating objects (In) & & & & $\begin{array}{c}0.507^{* * *} \\
(14.88)\end{array}$ \\
\hline Sets on free-swimming schools (In) & & & & $\begin{array}{c}0.285^{* * *} \\
(9.83)\end{array}$ \\
\hline Residual of rank of fishing hours (In) & & & & $\begin{array}{c}0.392^{* *} \\
(2.24)\end{array}$ \\
\hline Residual of rank of sets on floating objects (In) & & & & $\begin{array}{l}-0.063 \\
(-0.79)\end{array}$ \\
\hline Residual of rank of sets on free-swimming schools (In) & & & & $\begin{array}{l}-0.060 \\
(-1.09)\end{array}$ \\
\hline Rank of fishing hours (In) & $\begin{array}{c}0.002^{* * *} \\
(25.48)\end{array}$ & $\begin{array}{l}0.000 \\
(0.81)\end{array}$ & $\begin{array}{l}-0.000 \\
(-0.16)\end{array}$ & \\
\hline Rank of sets on floating objects (In) & $\begin{array}{c}0.000 * * * \\
(5.31)\end{array}$ & $\begin{array}{c}0.003^{* * *} \\
(31.69)\end{array}$ & $\begin{array}{l}0.000 \\
(1.25)\end{array}$ & \\
\hline Rank of sets on free-swimming schools (In) & $\begin{array}{c}0.000 * * \\
(2.27)\end{array}$ & $\begin{array}{l}0.000 \\
(0.01)\end{array}$ & $\begin{array}{c}0.003^{* * *} \\
(31.80)\end{array}$ & \\
\hline Skipper overall experience (In) & $\begin{array}{l}0.033 \\
(0.94)\end{array}$ & $\begin{array}{l}0.009 \\
(0.17)\end{array}$ & $\begin{array}{l}0.010 \\
(0.18)\end{array}$ & $\begin{array}{l}0.034 \\
(0.68)\end{array}$ \\
\hline Skipper vessel-specific experience (In) & $\begin{array}{l}-0.030^{*} \\
(-1.68)\end{array}$ & $\begin{array}{c}-0.064^{* *} \\
(-2.21)\end{array}$ & $\begin{array}{l}0.029 \\
(0.87)\end{array}$ & $\begin{array}{l}-0.011 \\
(-0.44)\end{array}$ \\
\hline Year fixed effects & YES & YES & YES & YES \\
\hline Skipper fixed effects & YES & YES & YES & YES \\
\hline $\begin{array}{l}\text { Vessel fixed effects } \\
\text { HO: } \ln (\text { FADS })=\ln \text { (free schools) }\end{array}$ & YES & YES & YES & YES \\
\hline F-stat ; prob. & $18.01 ; 0.000$ & $34.31 ; 0.000$ & $22.80 ; 0.000$ & $35.58 ; 0.000$ \\
\hline Number of observations & 1197 & 1197 & 1197 & 1197 \\
\hline Number of vessels & 60 & 60 & 60 & 60 \\
\hline Number of skippers & 159 & 159 & 159 & 159 \\
\hline $\mathrm{R}^{2}$ & 0.905 & 0.902 & 0.904 & 0.905 \\
\hline
\end{tabular}

Source: data from Observatoire Thonier, IRD, authors' calculations.

Note: robust standard errors are in parentheses. Significance levels are respectively $1 \%\left({ }^{* * *}\right), 5 \%\left({ }^{* *}\right)$ and $10 \%(*)$. 